\title{
Effects of a Flexibility and Relaxation Programme, Walking, and Nordic Walking on Parkinson's Disease
}

\author{
I. Reuter, ${ }^{1,2}$ S. Mehnert, ${ }^{1}$ P. Leone, ${ }^{2}$ M. Kaps, ${ }^{1}$ M. Oechsner, ${ }^{3}$ and M. Engelhardt ${ }^{4}$ \\ ${ }^{1}$ Department of Neurology, Justus Liebig University, Am Steg 14, 35392 Giessen, Germany \\ ${ }^{2}$ Soemmerring Institute, Bad Nauheim, Germany \\ ${ }^{3}$ Parkinsonklinik Bad Nauheim, Germany \\ ${ }^{4}$ Department of Orthopedics and Trauma surgery, Klinikum Osnabrück, 49076 Osnabrück, Germany \\ Correspondence should be addressed to I. Reuter, iris.reuter@neuro.med.uni-giessen.de
}

Received 1 October 2010; Revised 4 January 2011; Accepted 28 January 2011

Academic Editor: Ben Hurley

Copyright (๑) 2011 I. Reuter et al. This is an open access article distributed under the Creative Commons Attribution License, which permits unrestricted use, distribution, and reproduction in any medium, provided the original work is properly cited.

Symptoms of Parkinson's disease (PD) progress despite optimized medical treatment. The present study investigated the effects of a flexibility and relaxation programme, walking, and Nordic walking (NW) on walking speed, stride length, stride length variability, Parkinson-specific disability (UPDRS), and health-related quality of life (PDQ 39). 90 PD patients were randomly allocated to the 3 treatment groups. Patients participated in a 6-month study with 3 exercise sessions per week, each lasting 70 min. Assessment after completion of the training showed that pain was reduced in all groups, and balance and health-related quality of life were improved. Furthermore, walking, and Nordic walking improved stride length, gait variability, maximal walking speed, exercise capacity at submaximal level, and PD disease-specific disability on the UPDRS in addition. Nordic walking was superior to the flexibility and relaxation programme and walking in improving postural stability, stride length, gait pattern and gait variability. No significant injuries occurred during the training. All patients of the Nordic walking group continued Nordic walking after completing the study.

\section{Introduction}

Parkinson's disease (PD) is one of the most common neurodegenerative diseases with a prevalence of 100-200/100000 people worldwide [1-3]. The risk of developing PD increases with age. The clinical manifestation is characterised by specific motor deficits: bradykinesia, tremor, rigidity, and postural instability. While the UK brain bank criteria require the presence of bradykinesia combined with at least one of the other symptoms $[4,5]$ for diagnosis of Parkinson's disease, others do not consider that bradykinesia has to be always present and make the diagnosis of Parkinson's disease when two of these symptoms are present $[6,7]$.

The pathological definition of PD includes the loss of dopaminergic cells in the substantia nigra pars compacta with the subsequent lack of the neurotransmitter dopamine [8-12] and the presence of Lewy bodies [13]. Medical and surgical treatments provide symptomatic relief, but even with optimal therapy there is no cure for the disease and symptoms progress further [14]. PD patients tend to adapt a sedentary lifestyle very early in the course of the disease $[15,16]$ and have lower levels of strength $[17,18]$ and functional ability. This is caused by a combination of physical impairments, such as walking and balance problems, cognitive dysfunction with focus on executive dysfunction, depression, fatigue, and pain. Therefore, physical treatment gained in importance. A review on the effectiveness of exercise in $\mathrm{PD}$ has shown that exercise is effective at improving physical functioning, health-related quality of life (HRQL), leg strength, walking and balance $[19,20]$. However, there have not been sufficient data regarding dose, type and components of exercise programmes, and stage specific effects. Despite the interest in this area, only a few randomized clinical trials comparing different approaches of sports therapy are published so far.

We selected from our data base 500 PD patients who participated in sports. To choose appropriate sports activities for the study, we asked this group to complete a questionnaire. 
According to the patients replies, they liked the social aspects of sports activities and wanted to improve their health, fitness and mobility. Complex and difficult sport activities with an increased risk of falls were not preferred. Walking, Nordic walking, gymnastics, biking, and dancing were most popular. Nordic walking is a physical activity consisting of walking with poles similar to ski poles. It has evolved from an offseason ski training. The poles are designed for the purpose of activating the upper body during walking. The poles are equipped with rubber or spike tips and the walking itself resembles Nordic style skiing.

Patients are asked to walk in an upright position, not leaning forward or backward. The head should be up and looking forward and the poles are held close to the body. When the leading foot is moving forward, the opposite arm swings forward to waist height. The opposite pole strikes the ground level with the heel of the leading foot. The patients were reminded not to plant the pole in front of their feet. The poles remain pointing diagonally backward and the pole is pushed as far back as possible. The arm straightens and the hand is opening off the grip by the end of the arm swing. Nordic Walking is not expensive and can be performed round the year. Compared to walking, there is a stronger involvement of the upper body in Nordic Walking which might burn more calories [21, 22]. Furthermore, by using the poles, the muscles in the upper body can be activated, and the length of each step taken is supposedly increased, resulting in a faster gait $[23,24]$. The aim of the present study was to evaluate the effects of two aerobic training programmes, Nordic walking and walking and the effects of a combined flexibility and relaxation programme without aerobic components and the adherence to the allocated sports programmes after completion of the study period. The first hypothesis of the study was that all exercise programmes, irrespective of the mode of the training programme, improve (a) walking speed, (b) gait pattern, (c) balance, (d) symptoms of Parkinson's disease, and (e) cardiovascular parameters at maximal and submaximal intensity.

The second hypothesis was that the effects of Nordic walking are superior to those of the walking and the flexibility and relaxation programme.

\section{Patients and Methods}

2.1. Subjects. $90 \mathrm{PD}$ patients, 45 men and 45 women (UK brain bank criteria) [4], and a Hoehn \& Yahr stage II and III [25] were included in the study. Exclusion criteria were severe concomitant diseases, which limit physical performances, and a second neurological disease. All patients were assessed by a movement disorder specialist (IR, SM). Medical treatment was optimised prior to the study. It was aimed at keeping medication stable during the study. Demographic data included age, body length, body weight (patients were weighed at the beginning and end of the training programme), body mass index (BMI), duration of disease, weekly sports activity, smoking habits, and concomitant diseases (hypertension, chronic obstructive pulmonary disease, thyroid disease, diabetes mellitus, hypercholesterinaemia, osteoarthritis).
2.2. Design (Figure 1). Prior to the training patients underwent a medical examination [26] including a cardiovascular exercise test. A medical history was taken, and patients were screened for coronary heart disease, hypertension, pulmonary function, cardiopulmonary diseases, diabetes and osteoarthritis. Patients kept an activity log one week prior to the training programme and during the last week of the training period. Time spent sitting, doing light, moderate and heavy work was recorded.

Patients did not participate in other sports programmes during the study but were allowed to continue physiotherapy and participated in family leisure activities. These activities were recorded.

Patients were randomly allocated to one of the three training groups. Randomisation was conducted by using a computer-generated sequence. One training group performed Nordic walking (NW) training, 3 times per week for 6 months. Each session lasted 70 minutes and consisted of a warming up including some flexibility and strength exercises with and without the poles. One session per week was dedicated to practising NW technique, the other sessions focused on endurance training. Patients were encouraged to increase the intensity of the training by walking faster or uphill and to increase the distance walked. Each training session finished with a cooling down programme. Training sessions took place in a park and a forest near to the university hospital. Technical performance was assessed by video recording. In addition, NW instructors used a checklist for assessment of the technical skills (i.e., diagonal sequence, opening of the hands, and planting of the poles).

The second training group conducted a walking training. Training sessions were performed three times per week over 6 months. The training session also lasted $70 \mathrm{~min}$ and consisted of a warming up, technique training, endurance training and a cooling down. Instructors emphasised on arm swing and coordination of upper and lower limbs. One session per week included walking uphill to improve muscle strength.

The third group performed flexibility exercises and a relaxation training. The training took place in a gym. Each session lasted $70 \mathrm{~min}$. The training focused on stretching, improving balance and range of movements. The flexibility and relaxation programme did not include aerobic exercises, while aerobic fitness and endurance were additionally addressed by walking and NW training. Nordic walking is thought to be a more vigorous exercise than walking. Thus, the training programmes differ in the amount of aerobic exercises included. Three physiotherapists who were trained as NW instructors conducted the training sessions of the three groups.

The Borg scale was applied as a measure [27] for exertion to estimate the intensity of the training.

Since training should also help patients to adapt a more active life style, partners were offered six training sessions of the training programme, which was allocated to the patient.

Primary outcome measures were maximal walking speed on a treadmill ergometer, a $12-\mathrm{m}$ and $24-\mathrm{m}$ walking test, stride length and gait variability, assessed at different walking speeds, specific PD disability on the UPDRS 


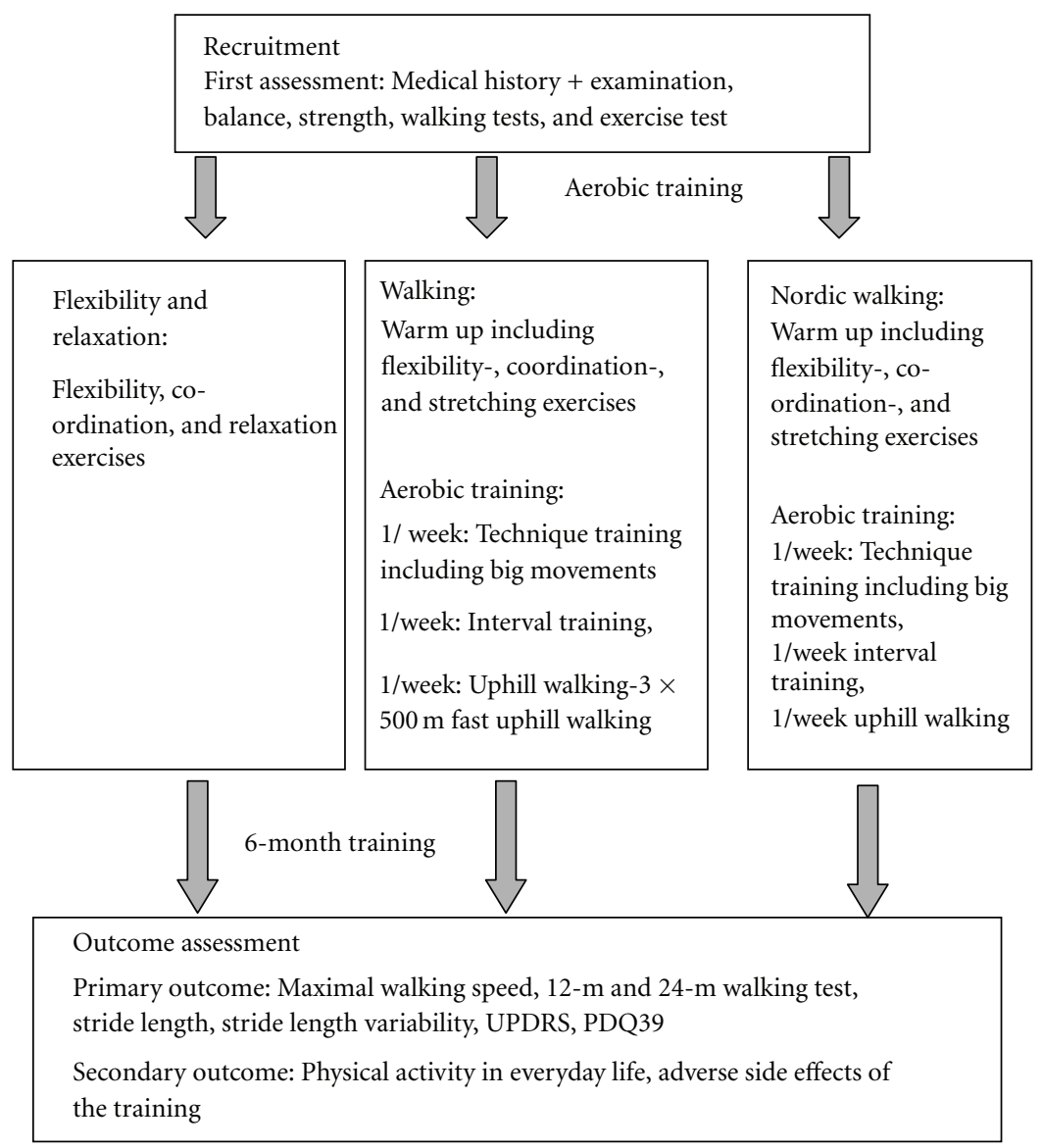

FIgUre 1: Study design.

(unified Parkinson's disease rating scale) [28] and HRQL (Parkinson's disease questionnaire 39; PDQ39) [29]. Outcome was assessed in all patients at baseline and after completion of the training period.

Secondary outcome measures were physical activity in everyday life and adverse effects of the training.

Adverse effects included cardiovascular side effects such as exercise-induced hypotension and injuries, caused by fall or overuse.

Outcome was assessed by two movement disorder specialists (IR, SM), who were blinded to the treatment arm.

2.3. Scales Used. The unified Parkinson's disease rating scale (UPDRS) is the most frequently used outcome measure in clinical trials in Parkinson's disease [28]. The UPDR scale has four subscales: part 1, which has 4 questions on mentation, behaviour, and mood (range $0-16$ points), part 2, which has 13 questions on activities of daily living (ADL) (range 0-52 points), part 3 , which has 14 questions on motor functions (range 0-108 points), and part 4, which has 11 questions on motor and other complications of advanced disease (0-23 points). The UPDRS-Sum score ranges from 0 to 199 points, with a higher score indicating greater problems.
Posture, postural stability, alternating movements and leg agility were assessed by the single items of the UPDRS motor scale (score of each item ranging between 0 and 4 points).

For assessment of health-related quality of life, patients filled in the Parkinson's disease-specific questionnaire (PDQ 39 ), which consists of 8 subscales: subscale 1 mobility ( $\max$ 40 points); subscale 2 activities of daily living (max 24 points), subscale 3 emotional well-being ( $\max 24$ points), subscale 4 stigma (max 16 points), subscale 5 social support (max 12 points), subscale 6 cognition (max 16 points), subscale 7 communication ( $\max 12$ points), and subscale 8 bodily discomfort (max 12 points) [29]. The sum score of raw data ranges from 0 to 156 points, with high scores indicating lower health-related quality of life. For better comparison of the results, raw data were transformed and expressed in percentages of maximal possible sum score.

For exclusion of significant depression and anxiety the hospital anxiety and depression scale was applied [30]. The scale consists of two subscales, an anxiety scale and a depression scale ranging from 0 to 21 points, respectively. Patients are asked to choose one response from the four given for each question. Patients were strongly encouraged to respond promptly. Questions related to anxiety are marked 
with $\mathrm{A}$ and to depression with D. Depression and anxiety are scored separately. On each scale 0 to 7 points indicate a normal, 8 to 10 points a borderline abnormal and 11 or more points an abnormal result.

Minimental state examination (MMSE) was used as screening tool for dementia. The test assesses orientation, registration, attention, calculation, recall, language, writing, and copying. The maximum score is 30 points; high scores indicate good performance [31]. Cut off criteria for an abnormal result are 24 points and below. Dementia is assumed for less than 20 points [32].

Pain was rated by using a visual analogue scale for several regions of the body (neck, arms, hands, back, iliosacral joint, hip, knees, feet, and toes). Pain was recorded to evaluate potential adverse events of the training, health risks, injuries and overuse injuries during the training period [33].

2.4. Balance. Balance was tested by using the Berg-Balance scale [34]. The test assesses balance in several different positions. The 14 items have a choice of 5 answers, numerically scored from 0 to 4 . Maximal sum score adds up to 56 points with a higher score indicating good balance.

\subsection{Walking Tests}

2.5.1. 12-m and 24- $m$ Webster-Walking Tests [35]. Patients were asked to walk as fast as possible a distance of $12 \mathrm{~m}$, and after a 5-minute break a distance of $24 \mathrm{~m}$ with a turn after $12 \mathrm{~m}$. The time was taken for the $12 \mathrm{~m}$ distance and the $24 \mathrm{~m}$ distance.

2.6. Assessment of Gait Parameters. Stride time (time from initial contact of one foot to subsequent contact of the same foot), percentage of double stance time ([time of bilateral foot contact/stride time] $\times 100$ ), stride length (distance from initial contact of one foot to subsequent contact of the same foot) and the coefficient of stride length ([standard variation/mean] $\times 100)$ [36-38] were assessed at different walking speeds on a motorized medical treadmill ergometer. There is sufficient evidence that gait variability is increased in basal ganglia disorders [39]. Furthermore, increased strideto-stride variability might reflect a failure of automatic stepping mechanisms [36]. Increased gait variability can be seen throughout the course of Parkinson's disease and has been found to be one aspect of walking, closely associated with risk of falls in the elderly [40-42].

For better comparison of the training effects patients walked at 6 different walking speeds $(1.5 \mathrm{~km} / \mathrm{h}, 1.8 \mathrm{~km} / \mathrm{h}$, $2.1 \mathrm{~km} / \mathrm{h}, 2.4 \mathrm{~km} / \mathrm{h}, 2.7 \mathrm{~km} / \mathrm{h}$, and $3 \mathrm{~km} / \mathrm{h}$ ) prior and after the training period. The treadmill was equipped with force platforms, that allowed an accurate determination of footground contact. Patients were not allowed to use the handrails of the treadmill for support.

2.7. Exercise Test. Patients performed a maximal exercise test on a medical motorized treadmill ergometer (Woodway PPS Med) and were instructed to walk on the treadmill. Switching to jogging was prohibited, since walking and jogging put different demands on the cardiovascular and muscular system. The test started at a walking speed of $3.0 \mathrm{~km} / \mathrm{h}$. Every 2-minute the speed was increased by $0.5 \mathrm{~km} / \mathrm{h}$. At the end of each 2-minute stage blood pressure (BP) and heart rate $(\mathrm{HR})$ were taken. $\mathrm{BP}$ and $\mathrm{HR}$ responses to maximal and submaximal exercise testing were recorded. Maximal exercise testing assesses the aerobic capacity and requires subjects to exercise to exhaustion. However, fatigue, pain, and muscle weakness might hinder patients from successfully completing the test. Therefore, we assessed as well performance at submaximal exercise intensity. Blood pressure and heart rate changes between resting conditions and maximal walking speed were recorded at baseline and final assessment. Maximal exertion was defined as reaching a heart rate of 220 - age or a perceived exertion of 17 on the Borg scale [27]; this means walking with very hard effort. For assessment of exercise capacity at submaximal level after completion of the training programme, two approaches were chosen:

(a) the BP and HR responses to increasing work load between a walking speed of $3 \mathrm{~km} / \mathrm{h}$ and $5 \mathrm{~km} / \mathrm{h}$ were assessed,

(b) BP and HR changes between resting conditions and the walking speed which corresponded to the maximal walking speed at the first assessment were recorded and compared to the $\mathrm{BP}$ and $\mathrm{HR}$ change between resting conditions and maximal walking speed at the first assessment.

Patients were secured with a safety harness, suspended from the ceiling, without weight support. Before testing patients were given $5 \mathrm{~min}$ to familiarise themselves with the treadmill locomotion. Patients were not allowed to use the handrails of the treadmill for support.

To assess the attractiveness of the exercise programme for the patients, all patients were contacted by phone six months after completion of the training period and a short telephone interview was conducted. Patients were asked the following questions.

(a) Do you continue the instructed training regime practiced during the course of the study?

(b) If not, did you stop exercising or did you switch to another sports activity?

(c) How often do you exercise per week?

(d) Do you exercise on your own or together with your spouse or your friends?

\section{Statistical Analysis}

Statistical analysis was conducted using IBM SPSS Statistics 18.0 (IBM, Somers, USA) statistical software. Formal power analysis was performed prior to the study. The results indicated that a sample size of 30 subjects per group was sufficient. The power analysis regarding the UPDRS was based on an improvement of the UPDRS motor scale by 5 points, which is clinically relevant according to the findings of Schrag et al. [43]. Demographic data on ordinal level were analysed by using a nonparametric test (Kruskall-Wallis). The Kruskall-Wallis test was also applied for the analysis 
TABLE 1

(a) Demographic data

\begin{tabular}{|c|c|c|c|}
\hline & $\begin{array}{l}\text { Flexibility and relaxation } \\
\text { group } \\
N=30\end{array}$ & $\begin{array}{l}\text { Walking group } \\
\qquad N=30\end{array}$ & $\begin{array}{l}\text { Nordic walking group } \\
\qquad N=30\end{array}$ \\
\hline & Mean \pm std & Mean \pm std & Mean \pm std \\
\hline Age (years) & $62.1 \pm 2.5$ & $63 \pm 3.1$ & $62 \pm 3.2$ \\
\hline BMI $\left(\mathrm{kg} / \mathrm{m}^{2}\right)$ & $27.16 \pm 4.38$ & $27.21 \pm 3.91$ & $26.37 \pm 3.6$ \\
\hline Length $(\mathrm{cm})$ & $171.87 \pm 5.9$ & $170.1 \pm 7.1$ & $171.84 \pm 7.5$ \\
\hline Body weight (kg) & $80.4 \pm 14.3$ & $78.87 \pm 13.1$ & $78.1 \pm 12.8$ \\
\hline $\begin{array}{l}\text { Duration of disease } \\
\text { (months) }\end{array}$ & $62.33 \pm 38.2$ & $71.9 \pm 50.5$ & $64.1 \pm 48.7$ \\
\hline $\begin{array}{l}\text { Weekly sports activity in } \\
\text { the past (min) }\end{array}$ & $120 \pm 17$ & $135 \pm 21$ & $118 \pm 19$ \\
\hline
\end{tabular}

(b) Comorbidity of PD patients

\begin{tabular}{|c|c|c|c|}
\hline Comorbidity & $\begin{array}{l}\text { Flexibility \& relaxation group } \\
\qquad N=30 \\
\text { Percentage }(\%)\end{array}$ & $\begin{array}{l}\text { Walking group } \\
\quad N=30 \\
\text { Percentage }(\%)\end{array}$ & $\begin{array}{l}\text { Nordic walking group } \\
\qquad N=30 \\
\text { Percentage }(\%)\end{array}$ \\
\hline Hypertension & 40 & 30 & 33 \\
\hline $\begin{array}{l}\text { Chronic obstructive } \\
\text { pulmonary disease (COPD) }\end{array}$ & 10 & 13.3 & 10 \\
\hline Coronary heart disease & 6 & 6.2 & 8.3 \\
\hline Thyroid disease & 16.7 & 16.7 & 20 \\
\hline Diabetes mellitus & 8 & 10 & 10 \\
\hline Hypercholesterinaemia & 40 & 40 & 33 \\
\hline Osteoarthritis & 36 & 40 & 36 \\
\hline
\end{tabular}

of improvement in posture, postural stability, alternating movements, freezing, gait pattern, and leg agility. Continuous data were analysed by using a One-way ANOVA. Results of the UPDRS, gait parameters and cardiovascular data were assessed by using the repeated measure analysis. The repeated measure analysis provides information about "between and within subjects" effects. Within subject effects give information about training effects over the assessment period. Linear trends were extracted by orthogonal polynomials and analysed for days and for trials (gait parameter). Linear trends showed if there was a systematic change of training effects over time. The interaction between groups and the linear trend of days yielded information about difference in the rate of improvement between groups. The betweensubject factor compared the overall treatment effect between the groups. Post hoc analysis was done using Bonferroni tests (corrected for multiple comparisons). Parametric data were tested for normal distribution by using the Kolmogorov Smirnov test. Significance level was set at 0.05 .

The study was approved by the Ethical Committee of the Justus-Liebig University Giessen, and all patients gave written informed consent.

\section{Results}

Demographic data of the participating patients are shown in Tables $1 \mathrm{a}$ and $1 \mathrm{~b}$. There were 4 smokers in the flexibility and relaxation group and 5 smokers in the walking and Nordic walking group, respectively. Baseline assessments did not reveal any statistical differences in demographic data, health condition, and fitness between the groups. There were no significant differences in severity of the disease 14 patients of the NW group, 15 of the Walking group, and 16 of the flexibility and relaxation group were in Hoehn \& Yahr stage II. All other patients were in Hoehn \& Yahr stage III. The randomisation procedure was successful. There were no drop outs during the study.

Table 2 shows the medication of the patients at the beginning of the study. Medication had to be adapted in 2 patients of the walking and the flexibility and relaxation group respectively and in 1 patient of the Nordic Walking group. Three patients reported wearingoff, 1 patient dyskinesias and 1 patient early morning dystonia. Since change of medication had been minor (increase of levodopa dosage by $50 \mathrm{mg}$ in 3 patients, reduction of levodopa dose by $100 \mathrm{mg}$ in one subject, and addition of entacapone in one case), the patients continued the study. All patients received one physiotherapy session per week.

All patients showed normal results in the MMSE screening test for dementia. Three patients scored in a range of mild depression at baseline on the HAD, two patients at the final assessment. None of the patients became depressed during the study. 
TABLE 2: Medication used by the patient groups.

\begin{tabular}{|c|c|c|c|c|c|c|}
\hline \multirow[t]{2}{*}{ Medication } & \multicolumn{2}{|c|}{ Relaxation and flexibility group $N=30$} & \multicolumn{2}{|c|}{ Walking group $N=30$} & \multicolumn{2}{|c|}{ Nordic walking group $N=30$} \\
\hline & Total number & $(\%)$ & Total number & $(\%)$ & Total number & $(\%)$ \\
\hline Levodopa & 20 & 66 & 22 & 73.3 & 20 & 66.7 \\
\hline Dopamine agonists & 27 & 90 & 26 & 86.7 & 26 & 86.7 \\
\hline Mao-Inhibitor & 12 & 40 & 13 & 43.3 & 12 & 40 \\
\hline COMT-Inhibitor & 11 & 36.7 & 12 & 40 & 10 & 33 \\
\hline Amantadine & 10 & 33 & 10 & 33 & 9 & 30 \\
\hline$\beta$-blockers & 4 & 13.3 & 3 & 10 & 3 & 10 \\
\hline ACE-inhibitors & 3 & 10 & 3 & 10 & 3 & 10 \\
\hline Antidepressants & 7 & 23.3 & 8 & 26.7 & 8 & 26.7 \\
\hline
\end{tabular}

$(\%)=$ percentage.

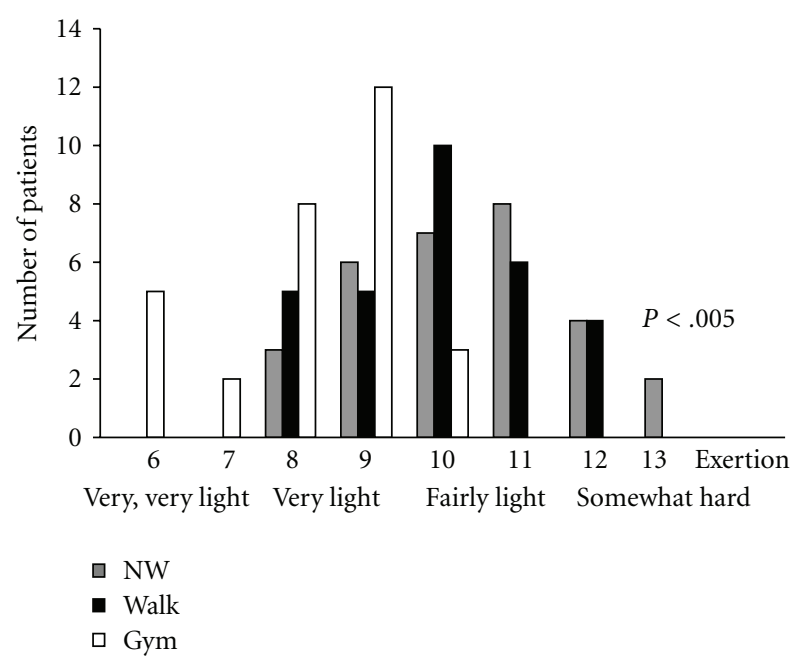

Figure 2: Borg scale: Patients of the Nordic walking group and walking group perceived more exertion than the flexibility and relaxation group suggesting that the training of both groups was more demanding.

All patients attended at least 70 of 78 training sessions offered. The attendance of training sessions was similar in all three groups. Figure 2 shows the overall rating of perceived exertion during the training sessions; participants of the flexibility and relaxation group rated the intensity of the training significantly lower $(F[2,89]=22.88 ; P<.005)$.

4.1. Assessment of Technical Skills. The technique of the Nordic walking training appeared to be very challenging for the patients. Patients had difficulties in opening the hands during the push-off phase. Furthermore, patients tended to carry the pole without weight loading with the more affected hand. However, the group managed to learn the Nordic walking technique, but the level of performance differed between the patients. 17 of the patients mastered the NW technique very well, 10 patients showed a good technical performance and 3 patients performed poorly. Both the NW group and the walking group had difficulties in employing a diagonal sequence and an interlimb coordination. Patients did not notice the technical deficits and depended on the coaching of the instructors.

4.2. Adverse Side Effects of the Training. Two patients of the NW group and one patient of the walking group experienced exercise-induced hypotension after intense walking uphill in hot weather. Patients felt dizzy but did not lose consciousness and recovered after fluid intake within $10 \mathrm{~min}$.

During the supervised 6-month training period, four patients of the NW group fell due to obstacles. The falls did not lead to severe injuries. Five patients twisted their ankles during cross-country walking, but only one patient complained of pain and missed three training sessions. Two patients of the NW group developed shoulder pain which required medical treatment with nonsteroidal antiinflammatory drugs. Both patients abstained from sports activities for one week.

Four patients of the walking group had falls during the supervised 6-month training period. Two patients tripped over roots and two patients slipped on wet ground while walking downhill. There was one fall in the flexibility and relaxation group during an attempt to stand up from the floor.

Muscle soreness was reported in all groups by $15 \%$ of the patients during the first three weeks of exercising.

4.3. Pain. Apart from the initial muscle soreness and the few injuries caused by falls and overuse, physical activity had a positive effect on pain. About $70 \%$ of patients complained of pain prior to the study. Table 3 shows the percentage of patients who suffered from pain in specific localisations of the body at baseline and after completion of the training. In the Nordic walking group up to $30 \%$ of patients became free of pain after the training. Furthermore, intensity of pain also decreased in patients, who still reported pain at the second assessment. Figures 3(a)-3(c) illustrate the decrease of pain severity in different areas of the body. Pain of the neck, hip, and iliosacral joint diminished in all groups likewise. Pain of the back $(F[2,59]=10.25 ; P<.001)$, hands $(F[2,35]=$ $12.44, P<.001)$, and legs $(F[2,29]=7.93 ; P<.002)$ was more eased by walking and NW than by the flexibility and relaxation programme. 
TABLE 3: Localisation of pain:comparison between baseline and final assessment.

\begin{tabular}{|c|c|c|c|c|c|c|}
\hline \multirow[t]{2}{*}{ Localisation of pain } & \multicolumn{2}{|c|}{ Flexibility \& relaxation group $N=30$} & \multicolumn{2}{|c|}{$\begin{array}{c}\text { Walking group } N=30 \\
\text { Percentage }(\%)\end{array}$} & \multicolumn{2}{|c|}{ Nordic walking group $N=30$} \\
\hline & Baseline & Final & Baseline & Final & Baseline & Final \\
\hline Neck & 53.3 & 40.0 & 56.6 & 43.3 & 53.3 & 40.0 \\
\hline Arm & 30.0 & 30.0 & 30.0 & 33.3 & 43.3 & 33.3 \\
\hline Hand, finger & 36.6 & 36.6 & 43.3 & 36.7 & 43.3 & 20.0 \\
\hline Chest & 23.3 & 26.6 & 20.0 & 20.0 & 20.0 & 20.0 \\
\hline Back & 73.3 & 43.3 & 66.6 & 40.0 & 73.3 & 40.0 \\
\hline Hip & 33.3 & 26.6 & 36.6 & 23.3 & 36.6 & 20.0 \\
\hline Iliosacal joint & 36.6 & 20.0 & 43.3 & 26.6 & 50.0 & 33.0 \\
\hline Leg & 30.0 & 26.6 & 33.0 & 26.6 & 36.6 & 20.0 \\
\hline Feet, toes & 26.6 & 26.6 & 23.3 & 23.3 & 26.6 & 20.0 \\
\hline
\end{tabular}

4.4. PD-Specific Disability. UPDRS score did not differ significantly at baseline assessment between the groups. The sum-score of the UPDRS decreased in the Nordic walking and walking group significantly between baseline and the final assessment $\left(F_{\operatorname{lin}}[1,87]=5.70 ; P<.02\right)$, which could be attributed to the improvement in the UPDRS subscale 3 (motor function) (Figure 4). There were clear group differences with lower scores for the walking and Nordic Walking groups at the final assessment indicating less Parkinson's disease-specific disability (UPDRS sum score: $F[2,87]=3,77 ; P<.05$; UPDRS motor score: $F[2,87]=$ 7.48; $P<.05$ ) (Figure 4). $83.3 \%$ of the NW group, $63.3 \%$ of the walking group, and $33 \%$ of patients of the flexibility and relaxation group improved more than 5 points on the UPDRS motor score (Chi-Quadrat $=25.82 ; \mathrm{df}=2, P<$ .001). The mean improvement of the UPDRS motor score amounted to $6.4 \pm 4.1$ points in the NW group and $4.4 \pm$ 5.1 points in the walking group. Patients, who performed a walking or NW training, had a better posture $(P<.01)$, showed less freezing $(P<.001)$, and were faster in alternating movements $(P<.003)$ at the final assessment. Nordic walking improved postural stability $(P<.004)$ and gait pattern $(P<.001)$ more than the walking and the flexibility and relaxation training.

Table 4 shows the percentage of patients, who improved in postural stability, posture, gait pattern, freezing, leg agility and alternating movements and the range of improvement.

4.5. HRQL. The score of the PDQ 39 decreased in all groups indicating a better health-related quality of life $\left(F_{\text {lin }}[1,87]=23.2 ; P<.001\right)$. Apart from subscale 6 , no differences between the groups neither at baseline nor at the second assessment were revealed. Subscale 6 reflects patients' estimation of their cognitive function. Patients who performed a walking or Nordic walking training felt that they could better concentrate, memorize, and recall information $(F[2,87]=4.09 ; P<.02)$.

4.6. Balance. There were no differences between groups at baseline testing on the Berg balance scale scores. Although patients performed on a high level at baseline $(\varnothing=48 \pm$ 2.1 points), they showed in particular difficulties in the functional reach test and the one leg stance. The majority of patients could reach less than $12.5 \mathrm{~cm}$ forward. All groups improved on the Berg-balance scale $\left(F_{\text {lin }}[2,87]=61.2 ; P<\right.$ $.001)$. There was no difference between the groups $(\varnothing=$ $51 \pm 1.8$ points).

4.7. 12- $m$ and 24- $m$ Webster Walking Test. There was no difference between the groups at baseline assessment (flexibility and relaxation group: $8.6 \pm 1.6 \mathrm{~s}$; walking: $8.0 \pm 1.1 \mathrm{~s}$; Nordic walking: $8.4 \pm 0.7 \mathrm{~s}$ ). All groups improved in walking velocity after 6 months $\left(F_{\text {lin }}[1,87]=138.13 ; P<.001\right)$. While the flexibility and relaxation group improved only slightly by $0.6 \mathrm{~s}$, there was a clear improvement of the NW group and walking group by $2.1 \pm 0.6 \mathrm{~s}$ and $1.8 \pm 0.7 \mathrm{~s}$, respectively, resulting in a clear interaction between group and days $(F[2,87]=13.96 ; P<.001)$. Thus, the time needed for the $12 \mathrm{~m}$ distance was significantly shorter for the Nordic walking and walking group $(F[2,87]=5.01 ; P<.01)$.

The improvement was even more significant in the $24-\mathrm{m}$ walking test. The walking and NW walking groups improved by $4.3 \mathrm{~s}$ and $4.7 \mathrm{~s}$, respectively, compared to $0.7 \mathrm{~s}$ in the flexibility and relaxation group $(F[2,87]=6.06 ; P<.01)$. The post hoc test revealed no difference between the walking and Nordic walking group.

4.8. Stride Length, Stride Length Variability, Stride Time, and Double Stance. Stride length increased with increasing walking speed in all groups on both days $\left(F_{\text {lin }}[1,87]=\right.$ $243.2 ; P<.001)$, but only the walking and Nordic walking group showed an increase of stride length after completion of the training compared to the baseline assessment. There was a significant interaction between groups and days $(F[2,87]=$ $31.08 ; P<.001)$ and a clear group effect $(F[2,87]=$ $3.588 ; P<.05)$.

The Nordic walking group was most effective in improving stride length. The post hoc test revealed that there was a clear difference between the Nordic walking and the flexibility and relaxation group $(P<.001)$ and a small 


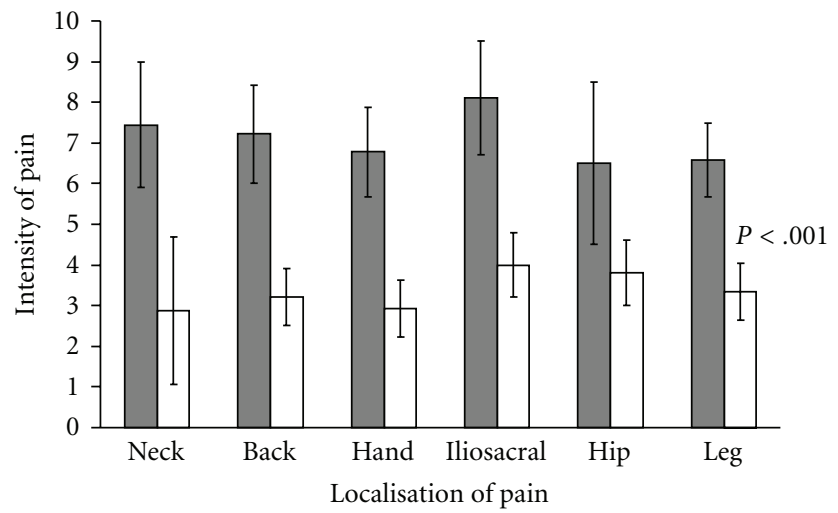

NW T0

口 NW T1

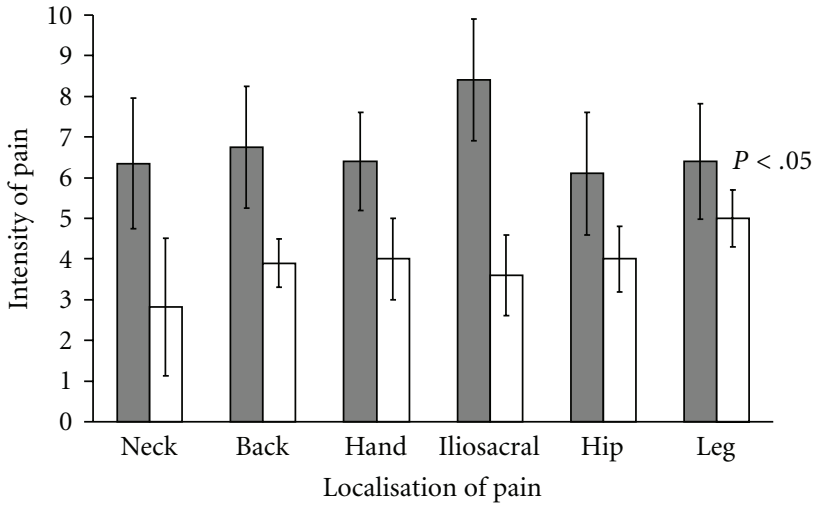

$\square$ Walking T0

$\square$ Walking $\mathrm{T} 1$

(a)

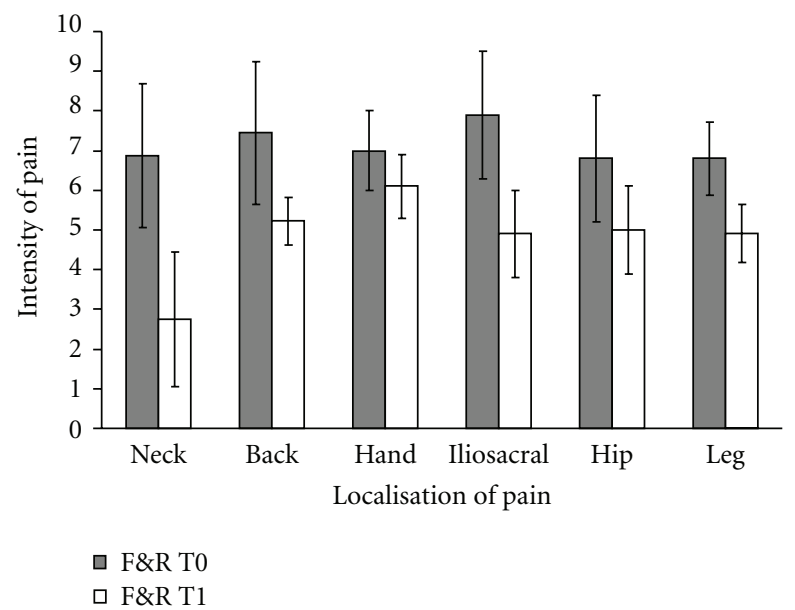

(c)

FIGURE 3: Intensity of pain was significantly lower at the second assessment compared to baseline assessment $(P<.001)$. Pain of the back, hands, and legs was more eased by the Nordic walking and walking group. (a) Nordic walking group T0 $=$ first assessment, T1 $=$ second assessment, error bars indicate standard deviations. (b) Intensity of pain in the walking group T0 = first assessment, T1 = second assessment, error bars indicate the standard deviation. (c) Intensity of pain in the flexibility and relaxation group $(\mathrm{F} \& \mathrm{R}) \mathrm{T} 0=\mathrm{first}$ assessment, $\mathrm{T} 1=$ second assessment, error bars indicate standard deviations.

but significant difference between the Nordic walking and walking group $(P<.05)$ (Figure 5(a)).

4.9. Stride Length Variability. Stride length variability was higher during slow walking indicating more instability. With increasing walking speed, stride length variability decreased in all groups. On the first day, the three groups did not differ in stride length variability, after completion of the training programmes stride length variability decreased in all groups $\left(F_{\text {lin }}[1,87]=205.4 ; P<.001\right)$. However, the improvement in stride length variability was only significant in the walking and NW group indicated by an interaction between group and days $(F[2,87]=25.9 ; P<.001)$. The improvement of stride length variability of the walking and NW group resulted in a significant group difference $(F[2,87]=29,51 ; P<.001)$. The post hoc test revealed that the NW group was superior to the flexibility and relaxation group $(P<.001)$ and the walking group $(P<.01)$ (Figure 5(b)).

The groups differed as well in the improvement of stride length variability with increasing walking speed on the second day. While the Nordic walking group improved further in stride length variability at a walking speed of $2.7 \mathrm{~km} / \mathrm{h}$ and $3.0 \mathrm{~km} / \mathrm{h}$, the walking and flexibility and relaxation group did rather deteriorate at the higher walking velocities $($ Day $\times$ trial $\times$ group $F[2,87]=3,24 ; P<.05)$. A decrease of stride length variability might be important to reduce the risk of falling (Figure 5(b)).

4.10. Stride Time. Stride time decreased with increasing walking speed, there was no significant difference between the groups on the first assessment. After the training period 
TABLE 4: Comparison of improvement in leg agility, alternating hand movements, posture, postural stability, freezing, and gait pattern between the training groups.

\begin{tabular}{|c|c|c|c|c|c|c|c|c|c|}
\hline \multirow{2}{*}{ Parameters } & \multicolumn{3}{|c|}{ Flexibility and relaxation group $N=30$} & \multicolumn{3}{|c|}{ Walking group $N=30$} & \multicolumn{3}{|c|}{ Nordic walking group $N=30$} \\
\hline & no & yes $1 \mathrm{pt}$ & yes 2 pts & no & yes $1 \mathrm{pt}$ & yes 2 pts & no & yes $1 \mathrm{pt}$ & yes 2 pts \\
\hline & \multicolumn{9}{|c|}{ Percentage $(\%)$} \\
\hline \multirow{2}{*}{ Leg agility left } & 60 & 30 & 10 & 23.3 & 36.7 & 40 & 20 & 30 & 50 \\
\hline & & \multicolumn{2}{|c|}{40} & \multicolumn{3}{|c|}{76.7} & & \multicolumn{2}{|c|}{$80(\%)$} \\
\hline \multirow[t]{2}{*}{ Leg agility right } & 56 & 40 & 3 & 23.3 & 40 & 36.7 & 16.7 & 40 & 43.3 \\
\hline & & \multicolumn{2}{|c|}{43} & \multicolumn{4}{|c|}{76.7} & \multicolumn{2}{|c|}{ 83.3 $(\%)$} \\
\hline \multirow{2}{*}{$\begin{array}{l}\text { Alternating } \\
\text { movements right } \\
\text { hand }\end{array}$} & 53.3 & 33 & 13 & 30 & 43.3 & 26.7 & 23.3 & 30 & 46.7 \\
\hline & & \multicolumn{2}{|c|}{46} & \multicolumn{3}{|c|}{70} & & \multicolumn{2}{|c|}{ 76.7(\%) } \\
\hline \multirow{2}{*}{$\begin{array}{l}\text { Alternating } \\
\text { movements left } \\
\text { hand }\end{array}$} & 60 & 20 & 20 & 30 & 40 & 30 & 26.7 & 33 & 40 \\
\hline & & \multicolumn{2}{|c|}{40} & \multicolumn{3}{|c|}{70} & & \multicolumn{2}{|c|}{$73(\%)$} \\
\hline \multirow{2}{*}{ Posture } & 43.3 & 23.3 & 33 & 36.7 & 36.7 & 26.7 & 20 & 40 & 40 \\
\hline & & \multicolumn{2}{|c|}{56.3} & \multicolumn{3}{|c|}{63.7} & & \multicolumn{2}{|c|}{$80(\%)$} \\
\hline \multirow{2}{*}{ Freezing } & 53.3 & 36.7 & 10 & 23.3 & 40 & 36.7 & 20 & 40 & 40 \\
\hline & & \multicolumn{2}{|c|}{46.7} & \multicolumn{3}{|c|}{76.7} & & \multicolumn{2}{|c|}{$80(\%)$} \\
\hline \multirow{2}{*}{ Postural stability } & 46.7 & 43.3 & 10 & 36.7 & 26.7 & 36.7 & 16.7 & 40 & 43.3 \\
\hline & & \multicolumn{2}{|c|}{53.3} & \multicolumn{3}{|c|}{63.7} & & \multicolumn{2}{|c|}{ 83.7(\%) } \\
\hline \multirow{2}{*}{ Gait pattern } & 50 & 43.3 & 6.7 & 40 & 23.3 & 36.7 & 13.3 & 33 & 53.3 \\
\hline & & \multicolumn{2}{|c|}{50} & & & & & & \\
\hline
\end{tabular}

The first column indicates the percentage of patients who did not improve, the next column the percentage of patients who improved by 1 point, and the second column indicates the percentage of patients who improved by 2 points. The Bold value presents the percentage of all patients of a group who improved regardless of the amount of improvement.

stride time decreased further, shown in a linear trend of days $\left(F_{\text {lin }}[1,87]=120.6 ; P<.001\right)$. Since the Nordic walking and walking group improved more, an interaction between groups and days was found (day $\times$ group $F_{\text {lin }}[1,87]=$ $18.132 ; P<.001)$.

The Nordic walking group was superior to the walking group and the flexibility and relaxation group, shown in a clear between-subject effect $(F[2,87]=3,263, P<.05)$.

4.11. Double Stance. The double stance phase decreased with increasing walking speed in all groups on both assessments. Compared to the baseline test, the double stance phase was shorter on the second assessment in all groups $\left(F_{\text {lin }}[1,87]=\right.$ 1857.24; $P<.001$ ), but the reduction of the double stance phase was only significant in the walking group and NW group, resulting in a significant interaction between groups and days $(F[2,87]=83.08 ; P<.001)$ and a significant difference between the groups $(F[2,87]=64.29 ; P<.001)$ (Figure 5(c)).

4.12. Exercise Test. All groups showed already a good performance level at baseline assessment with a mean maximal walking speed of $6.0 \pm 1.1 \mathrm{~km} / \mathrm{h}$; the maximal walking speed did not differ significantly between the groups.

While the flexibility and relaxation group reached with $6.0 \pm 0.4 \mathrm{~km} / \mathrm{h}$ the same walking speed on the second assessment as on the first assessment, the walking and NW group improved further. The NW group managed on average $7.6 \pm 0.6 \mathrm{~km} / \mathrm{h}$ at the second assessment, the walking group $6.8 \pm 0.4 \mathrm{~km} / \mathrm{h}$. The NW group was significantly faster than the flexibility and relaxation group, shown in the interaction between group and days $(F[2,87]=21.11, P<.001)$ and a clear group effect $(F[2,86]=8,165 ; P<.001)$. The walking group did not differ significantly from the flexibility and relaxation group and the Nordic walking group.

4.13. Cardiovascular Effects. Blood pressure and heart rate at resting conditions were similar on the first and second assessment. Blood pressure and heart rate changes between resting conditions and the respective maximal walking speed on the first and the second assessment did not significantly differ between the groups.

On both days $30 \%$ of each training group reached maximal exertion according to the formula maximal heart 
TABLE 5: Time spent sitting per day and doing heavy work per week.

\begin{tabular}{|c|c|c|c|c|}
\hline Time spent & $\begin{array}{l}\text { Flexibility \& relaxation } \\
\text { group } N=30\end{array}$ & $\begin{array}{l}\text { Walking group } \\
\qquad N=30\end{array}$ & $\begin{array}{l}\text { NW group } \\
N=30\end{array}$ & Significance (group effect) \\
\hline Sitting per day baseline (h) & $9.11 \pm 2.34$ & $7.9 \pm 1.86$ & $8.11 \pm 1.61$ & \multirow{2}{*}{$F(2,87)=14.218 ; P<.001$} \\
\hline Sitting per day final (h) & $8.9 \pm 2.12$ & $5.7 \pm 2.4$ & $5.60 \pm 1.80$ & \\
\hline $\begin{array}{l}\text { Doing heavy work per week } \\
\text { baseline }(\mathrm{h})\end{array}$ & $4.7 \pm 3.1$ & $5.87 \pm 3.3$ & $5.2 \pm 3.12$ & \multirow{2}{*}{$F[2,87]=11.254 ; P<.001$} \\
\hline $\begin{array}{l}\text { Doing heavy work per week final } \\
\text { (h) }\end{array}$ & $3.8 \pm 3.41$ & $6.33 \pm 3.12$ & $9.4 \pm 3.12$ & \\
\hline
\end{tabular}

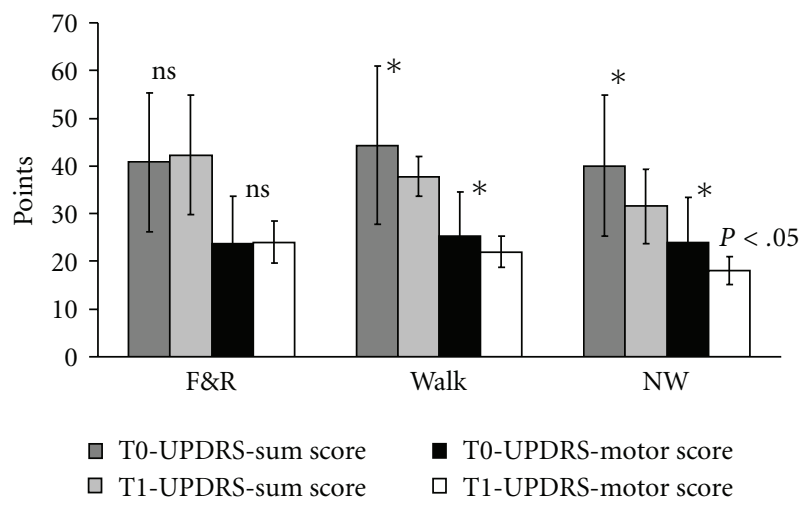

FIgURE 4: The UPDRS sum score and UPDRS motor score (subscale 3) did not decrease in the flexibility and relaxation group but decreased significantly in the Nordic walking and walking group resulting in a group effect. T0 $=$ first assessment, $\mathrm{T} 1=$ second assessment, $\mathrm{F} \& \mathrm{R}=$ Flexibility and Relaxation ${ }^{*} P<.05$, error bars indicate standard deviation.

rate $=220$-age. When patients were asked to rate their perceived exertion on the Borg scale, $50 \%$ of the patients classified their effort as very hard, $10 \%$ as very, very hard and the remaining patients as hard. There was no difference between the groups. According to the Borg scale, $60 \%$ of the patients reached maximal exertion.

To evaluate whether the training led to a better adaptation to exercise the course of the $\mathrm{BP}$ and $\mathrm{HR}$ response to exercise between $3 \mathrm{~km} / \mathrm{h}$ and $5 \mathrm{~km} / \mathrm{h}$ was assessed. This approach includes the $\mathrm{BP}$ and $\mathrm{HR}$ responses to exercise at a submaximal level. Patients who managed $5 \mathrm{~km} / \mathrm{h}$ on both days were included in the analysis. However, only 72 of the patients ( 25 of the flexibility and relaxation group, 23 of the walking group, and 24 of the NW group) were included in this calculation, since 18 patients did not reach $5.0 \mathrm{~km} / \mathrm{h}$ at the first or second assessment.

Comparison of systolic and diastolic blood pressure between $3 \mathrm{~km} / \mathrm{h}$ and $5 \mathrm{~km} / \mathrm{h}$ showed a better efficiency of the cardiovascular system to adapt to exercise in the Nordic walking and walking group. The submaximal walking speeds were less demanding for the patients after the training period. This is shown in a significant linear trend for days (systolic BP: $F_{\text {lin }}[1,69]=16.99 ; P<.001$; diastolic BP $\left.F_{\text {lin }}[1,69]=6.75 ; P<.01\right)$. The systolic blood pressure of the walking and Nordic walking group dropped significantly more than the systolic blood pressure of the flexibility and relaxation group, indicated by the interaction between groups and days $(F[2,69]=4.43 ; P<.001)$ (Figures $6(a)-$ $6(c))$. However, there was neither a significant group effect for the systolic nor for the diastolic blood pressure.

The heart rate was lower in all groups on the second assessment shown in a significant linear trend for days $\left(F_{\text {lin }}[1,70]=4.38 ; P<.01\right)$. However, the Nordic walking (Figure $7(\mathrm{a})$ ) and walking (Figure $7(\mathrm{~b})$ ) showed a significant lower heart rate at all walking speeds of the exercise test, while the flexibility and relaxation group showed a lower heart rate at low walking speeds only (Figure $7(\mathrm{c})$ ). Consecutively, there was a clear interaction between groups and days $(F[2,69]=3.82 ; P<.05)$ and a clear group effect $(F[2,69]=8.91 ; P<.001)$. Post hoc test (Bonferroni) revealed that the heart rate of the Nordic walking group was lower than the heart rate of the walking $(P<.05)$ and flexibility and relaxation group $(P<.001)$.

In order to get information on the adaptation to exercise of all patients a second analysis was performed. A different approach was chosen for this calculation. The blood pressure changes between resting conditions and the blood pressure at the walking speed, which corresponds to the maximal walking speed of the first day, were analysed on the second assessment and compared with the blood pressure changes between resting conditions and maximal walking speed on the first assessment. The mean systolic blood pressure change was significantly lower on the second assessment $\left(F_{\text {lin }}[1,87]=65.24 ; P<.001\right)$ in all groups. The blood pressure change of the Nordic walking and walking group was significantly lower than the blood pressure of the flexibility and relaxation group on the second assessment. Hence, there was an interaction between days and groups $(F[2,87]=21,11 ; P<.001)$, and a clear group effect $(F[2,86]=8.17 ; P<.001)$ was found. The diastolic blood pressure changes were significantly lower on the second assessment in all groups, shown in a significant linear trend $\left(F_{\text {lin }}[1,87]=28.26 ; P<.001\right)$.

The heart rate change between resting conditions and the walking speed corresponding to the maximal walking speed of the baseline assessment was lower at the second assessment, indicating an adaptation to exercise. The Nordic walking group and the walking group improved more than the flexibility and relaxation group, which is shown by an interaction of groups and days $(F[2,87]=3.64 ; P<.03)$ and a clear group effect $(F[2,87]=6.75 ; P<.002)$. 


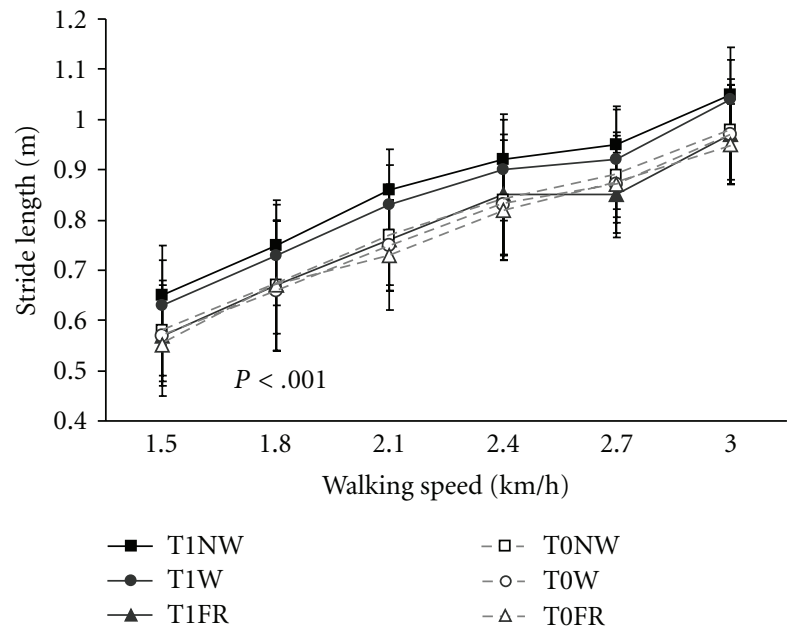

(a)

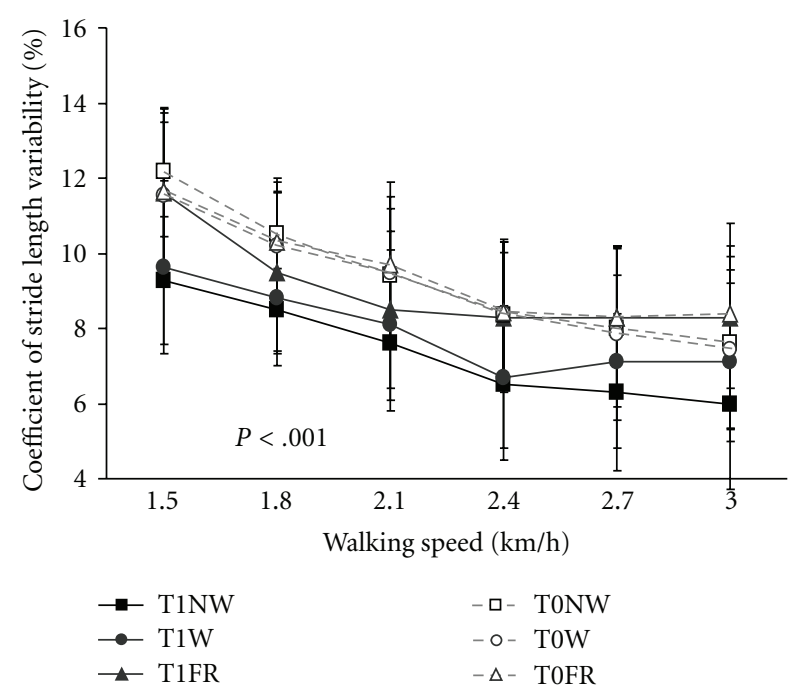

(b)

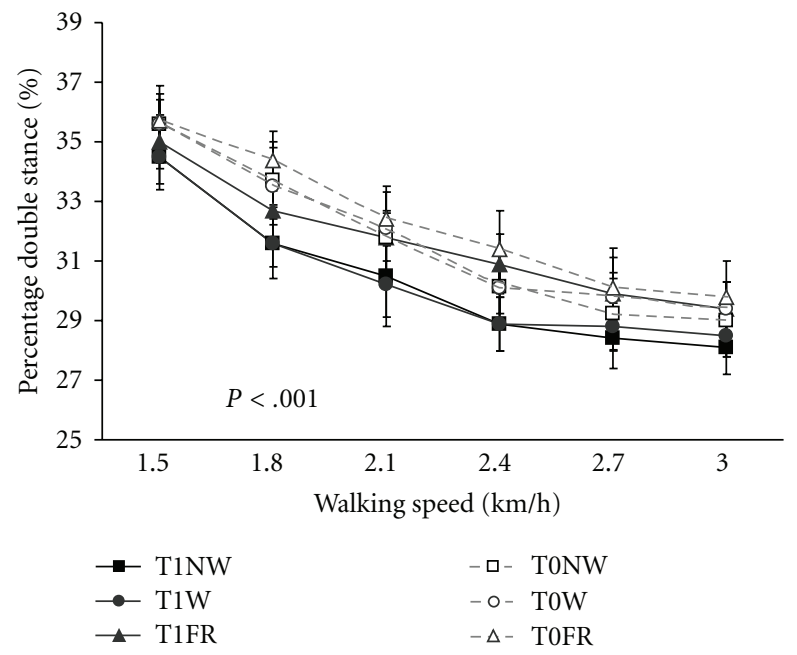

(c)

FIGURE 5: (a) Stride length increased significantly with increasing walking speed, and improved further on the second assessment $(P<.001)$. Stride length improved significantly more in the Nordic walking and walking groups than in the flexibility and relaxation group $(P<.001)$. $\mathrm{T} 0$ = first assessment; $\mathrm{T} 1$ = second assessment, error bars indicate the standard deviation. (b) Stride length variability improved most in the Nordic walking group. Nordic walking training was superior to walking $(P<.01)$ and the flexibility and relaxation programme $(\mathrm{F} \& \mathrm{R})$ $(P<.001)$. T0 = first assessment; T1 = second assessment, error bars indicate the standard deviation. (c) The duration of the double stance phase decreased with increasing walking speed in all groups but significantly more in the Nordic walking and walking group $(P<.001)$; T0 = first assessment, $\mathrm{T} 1$ = second assessment, error bars indicate the standard deviation.

Patients were asked to keep an activity log for one week prior to the training period and during the last week of the study. While there was no difference in general physical activity of the groups prior to the training, patients of the walking and Nordic walking groups spent more time doing heavy work, such as gardening, and spent less time sitting than the flexibility and relaxation group after six months training (Table 5).

The patients were on average slightly overweight at the beginning of the training (Table 1). The BMI in all groups was $>25$. Despite the mild increase of daily activity, patients did not lose weight during the training.

Six months after completion of the study, patients were asked whether they were still exercising. All patients of the NW group continued and had formed training groups. They walked with an instructor once a week. $60 \%$ of the participants of the walking group continued walking 2-3 times per week, $10 \%$ gave up exercising and $30 \%$ started practising NW. The flexibility and relaxation programme seemed to be less attractive. It was difficult to find a gym, 

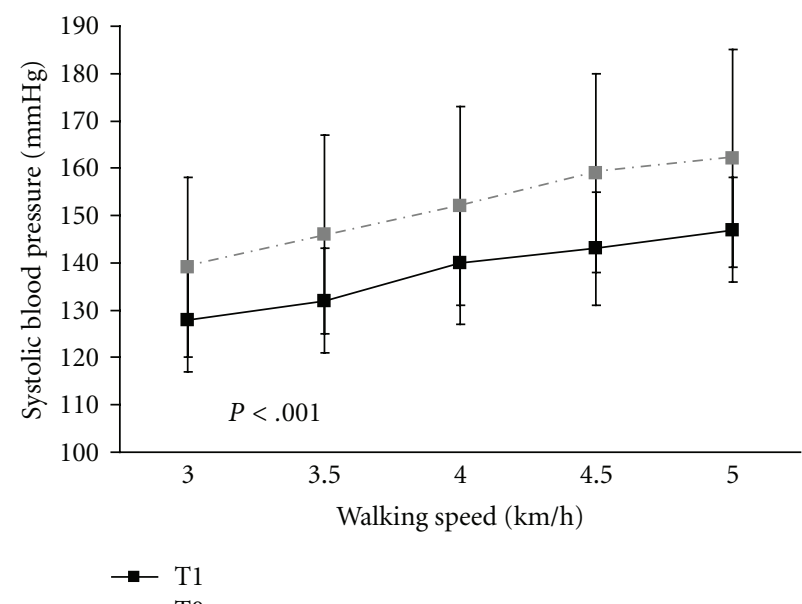

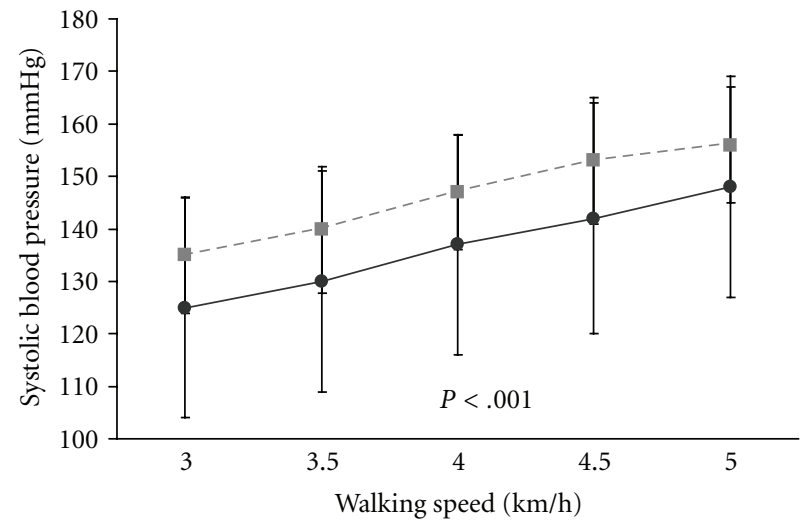

$\rightarrow \mathrm{T} 1$

- - - T0

(a)

(b)

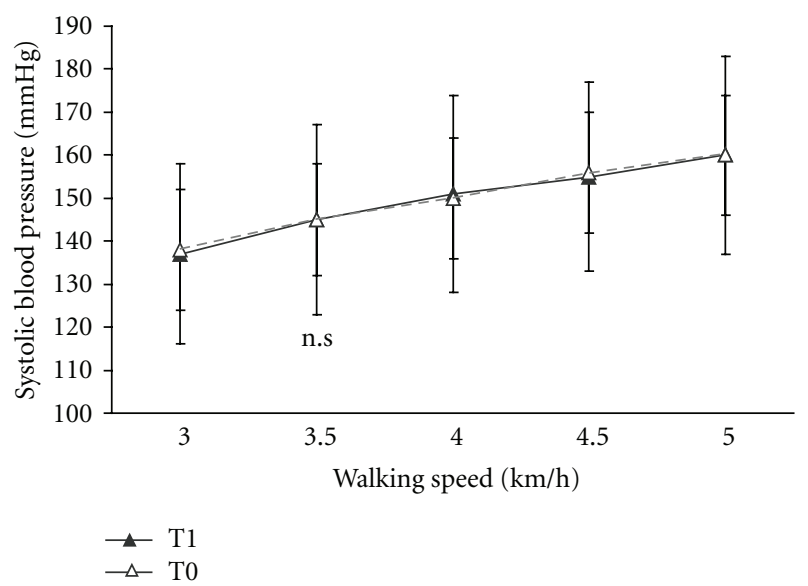

(c)

FIGURE 6: (a) The increase of the systolic blood pressure with increasing walking speed was significantly lower after completion of the training programme in the Nordic walking $((\mathrm{a}))$ and the walking group $((\mathrm{b}))$ but not in the flexibility and relaxation group; $((\mathrm{c}))$ T0 $=$ first assessment, $\mathrm{T} 1=$ second assessment, error bars indicate the standard deviation. (b) Walking group. T0 = first assessment, T1 = second assessment, error bars indicate the standard deviation. (c) Flexibility and relaxation group, there was no difference between the first and second assessment; T0 = first assessment, $\mathrm{T} 1=$ second assessment, error bars indicate the standard deviation.

and patients were more dependent on a physiotherapist to run the sessions. Only 50\% of the patients continued the flexibility and relaxation programme.

\section{Discussion}

In summary, the main results of the study were that all training programmes provided some benefit for the patients. Pain of the neck, hips, and iliosacral joint, healthrelated quality of life, and balance improved in all groups. In contrast maximal walking speed, stride length, double stance, exercise capacity at submaximal level, subscale 6 (cognition) of the PDQ 39 and the UPDRS Sum score and UPDRS-motor score improved only in the walking and NW group significantly. Patients, who completed a walking or Nordic walking training, had a better posture and postural stability, showed less freezing, and were faster in alternating movements. NW was superior to walking and the flexibility and relaxation programme in improving postural instability, gait pattern, stride length and stride length variability. The exercise programmes were not associated with an increased risk of falls or injuries.

Based on the results of the study, the first hypothesis that all training programmes improve walking speed, gait parameters, balance, cardiovascular parameters, Parkinson specific symptoms, pain, and HRQL can be partly corroborated only. The flexibility and relaxation programme did not improve significantly maximal walking speed on the treadmill, cardiovascular capacity, stride length and Parkinson's specific disability.

Gait and/or mobility were the outcome measures in most studies. Neurological symptoms served rarely as outcome measures for exercise programmes, and only a few studies found significant benefit in direction of exercise 


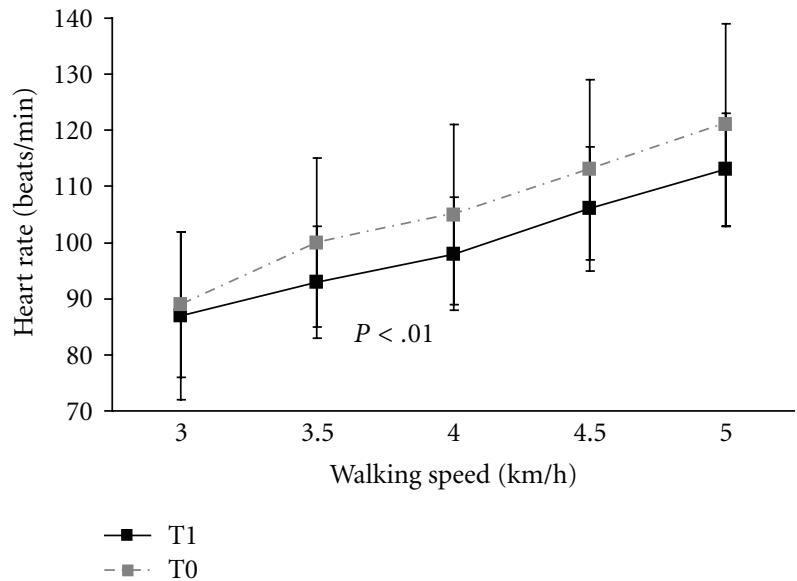

(a)

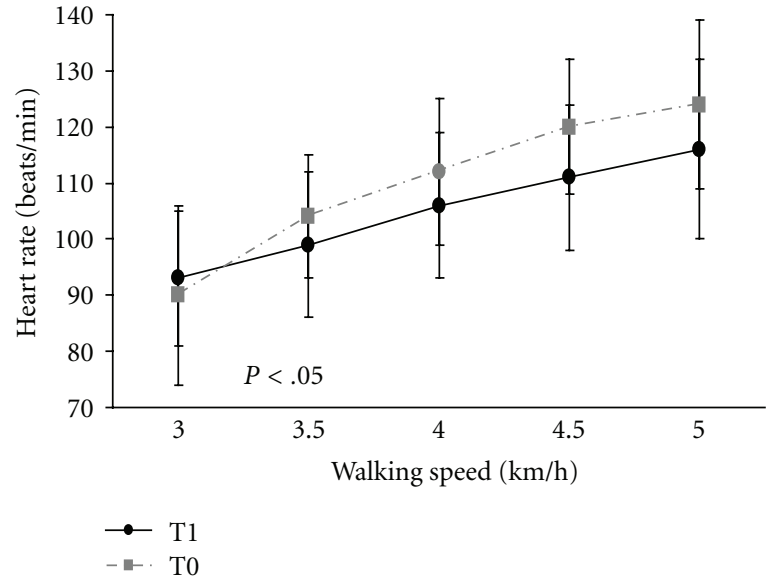

(b)

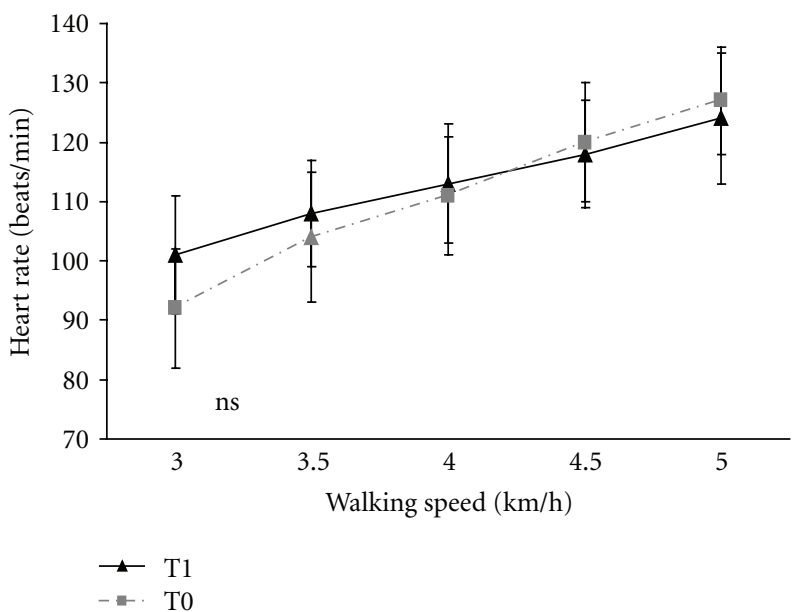

(c)

FIgURE 7: (a) Heart rate increase at submaximal walking speeds was lower in the Nordic walking ((a)) and walking group ((b)) than in the flexibility and relaxation group $((\mathrm{c}))$ at the second assessment resulting in a significant group effect $(P<.001)$. T0 = first assessment, T1 $=$ second assessment, error bars indicate the standard deviation. (b) Walking group: The heart rate response to exercise was significantly lower on the second assessment. T0 = first assessment, T1= second assessment, error bars indicate the standard deviation. (c) The heart rate of the flexibility and relaxation group (F\&R) was only significantly lower at low but not at higher walking speeds. Therefore, the course of heart rate response to exercise was not significantly lower on the second assessment in the F\&R group; T0 = first assessment, T1 = second assessment, error bars indicate the standard deviation.

intervention [44]. In the present study, we found a clinical relevant improvement on the UPDRS score. Analysis of the results shows that the improvement can be referred to the improvement of the motor scale, especially freezing, posture, alternating movements, walking pattern, and postural instability. Schrag et al. [43] have shown that a reduction of the UPDRS motor scale by 5 points is clinically relevant. The Nordic walking training resulted in a mean improvement of $6.4 \pm 4.1$ points of the UPDRS motor scale, while the walking group failed to reach a 5-point improvement despite the significant reduction of motor disability compared to baseline. $83.3 \%$ of the NW group, $63.3 \%$ of the walking group, and $33 \%$ of patients of the flexibility and relaxation group improved by more than 5 points on the UPDRS motor score as stated above. Neurological signs such as rigidity and tremor were not improved by exercise treatment, but it is to note that walking and Nordic walking had positive effects on some key symptoms of PD such as posture, alternating movements, freezing, and postural stability. These symptoms have major impact on mobility and the risk of falling. However, the UPDRS might not be sensitive enough to detect the differences generated by the exercise training.

Schenkman and Butler [45] proposed that a restricted range of motion of axial structures might contribute to loss of postural control, gait impairment and decline in overall function. Several studies have shown that trunk flexibility is associated with balance control [46]. Exercises, designed to improve axial range of motion, were shown to improve functional reach distance [46] and timed gait tasks. This might explain that improvement of balance was observed 
in all groups even in the flexibility and relaxation group. Posture and postural instability were most improved by NW. Supported by the poles patients walked cross-country during the training, and it has been shown that a training, which challenges the balance control, can improve the postural stability and gait control [47]. The cross country training has possibly improved balance so far that subjects of the NW group are also more stable without poles. Furthermore, the poles represented external triggers [15], and patients remembered to use the more affected arm to handle the pole. The increased involvement of the more affected hand in motion sequences might have led to an improvement of the agility of the more affected hand.

In contrast to the findings of Schenkman et al. [46], the flexibility and relaxation programme did not improve the walking speed in the Webster walking test in the present study. It is well accepted in competitive sport that training has to be specific [48]. This is known as the SAID principle (Specific adaptation to imposed demands). Therefore, walking and NW training resulted in more specific adaptations with regard to the outcome measures. The importance of the specificity of training is shown in the results of the $12-\mathrm{m}$ and 24-m walking tests and the exercise test on the treadmill. Walking and Nordic walking improved walking speed and gait parameters most. Thus, the specific walking training was superior to the flexibility and relaxation programme regarding walking speed, stride length and gait variability.

In agreement with other studies $[5,49,50]$, the majority of patients reported a better health-related quality of life at the end of the study independent of the training programme. Since patients enjoyed the social aspects of the training, emotional aspects might contribute to this improvement. Interestingly, the patient group with the greatest perceived exertion improved most on the subscale 6 (cognition) of the PDQ39 and reported better concentration and memory. There is a large body of studies reporting beneficial effects of endurance exercises on cognitive functions especially executive functions [51]. However, we did not perform a formal cognitive test battery after completion of the 6-month training period. At baseline assessment, all patients scored in a normal range on the MMSE although this test does not assess executive functions in particular.

The second hypothesis that Nordic walking is generally superior to the flexibility and relaxation programme and walking could not be confirmed. In most of the tests, Nordic walking was only superior to the flexibility and relaxation programme but not superior to the walking group, especially in the exercise test. It was expected that Nordic walking is most effective in increasing cardiorespiratory capacity. However, there was no superiority of the NW group. Earlier studies purported an enhancement of cardiovascular metabolism and an increase in walking speed by NW. However, recent studies have shown that the physiological effects of NW depend largely on the technical skills of the individuals. Without being competent in using the correct NW technique patients cannot exercise with high intensity. The participants of the NW group had difficulties to employ the correct technique in the beginning of the training period, and it took a long time until they involved the upper body. Although, at the end of the training period nearly all patients showed at least good technical skills, at the assessment after 3-month training, only 50\% of the patients showed good technical skills. Probably due to these technical difficulties, most of the patients of the NW group did not walk significantly faster with poles for most of the training period. Therefore, the metabolic and cardiovascular demands on the body might not have been much higher than in the walking group. Consequently, the effects of walking and NW walking might have been quite similar.

However, PD patients were able to learn the technique of NW. There is growing evidence that the capacity to learn remains in early stages of $\mathrm{PD}[52,53]$. In a previous study (unpublished data so far), we had shown that PD patients learnt a throwing task comparably to healthy age-matched subjects, but their performance level dropped significantly more than that of healthy subjects between the training sessions. A similar learning pattern was observed in the present study, patients who managed the push-off phase at the end of a training session had again difficulties in the next training session. Therefore, the 6-month study period might have been still too short to detect different effects of walking and NW training.

Cardio-respiratory capacity increases by adaptations of muscle fibres, better muscle recruitment, and improvement of cardio-respiratory parameters. PD patients have deficits in muscle recruitment and development of dynamic muscle strength. During the first weeks of training, the body learns to recruit the correct muscles in a proper sequence while inhibiting unnecessary muscle recruitment. These adaptations take several months to occur and depend on a specific training. Since walking was not practised in the flexibility and relaxation group, gait parameters and walking speed did not improve significantly. In addition, fitness training involves systematic progressions that apply the overload principle to purposeful short- and long-term goals [48]. The overload principle states that, for adaptations to occur, a threshold level must be exceeded. Cardio-respiratory capacity improves when an adequate stimulus is set. The demands of the walking and NW training on the body were greater than the demands of the flexibility and relaxation programme. Accordingly patients of the walking and NW group perceived a higher degree of exertion during the training than the flexibility and relaxation group. The ability of the patients of the walking and NW group to realise a higher walking speed with lower blood pressure levels and a lower heart rate showed the successful adaptation to exercise. Although studies on cardiovascular parameters are inconsistent, there is some evidence that $\mathrm{PD}$ patients can improve oxygen consumption by aerobic conditioning programmes $[46,54]$. Since oxygen consumption was not measured in the present study, we cannot claim that cardiovascular fitness of the patients had improved. At least lower increases of blood pressure and heart rate during the exercise test in patients having completed a walking or Nordic walking training programme can likely be attributed to a better efficiency of the cardiovascular system.

We did not specifically assess the effect of the exercise programme on concomitant diseases. However, the capacity 
of the patients to respond to demands on the cardiovascular system with a lower blood pressure increase after completion of the training has to be regarded as a positive effect of the training.

It is always desired to have a carry-over effect of the exercise training into daily life. However, the carry-over effect in PD is often small. PD patients often use cognitive strategies during exercises. As long as the patients are cognitively intact and do not have marked postural instability, they are immediately able to walk faster and with long steps. During the training sessions, patients are focused on walking and their attention is directed to the desired movement patterns. Patients might compensate for the neurotransmitter imbalance through bypassing the defective basal ganglia and instead using the frontal cortex to regulate movement size and timing $[55,56]$. Therefore, patients are often not able to keep the gait pattern, when they are distracted. We did not assess whether there was an improvement of gait pattern in every day life. However, the walking and Nordic walking training had an impact on the activities of daily life. Patients became more active and spent less time sitting during the day and instead more time doing heavy work during the week. This is in agreement with findings from a previous study [49].

Another positive effect was the reduction of pain, especially of musculoskeletal pain. Pain is one of the most common nonmotor symptoms in PD and leads to reduction of physical activity, since patients fear an increase of pain by movements. Pain in PD is thought to have several origins; either neuropathic pain that is central in nature, increasing during off-phases, or musculoskeletal pain. The latter responds well to physical therapy and exercises. This was confirmed in the present study. About $36 \%$ of the subjects participating in the study suffered from osteoarthritis. Osteoarthritis is often associated with pain and leads to a decreased range of joint motion and to a reduction of physical activity which is especially detrimental to PD patients. The neurodegenerative disease already induces rigidity, a reduction of joint movement leads to slow movements. Pain can start a vicious circle and leads to a significant loss of muscle strength and mobility. There is now sufficient evidence that muscle weakness, immobility, and neurodegenerative diseases are risk factors for osteoarthritis $[57,58]$. Current treatment regimes include exercise programmes to recover muscle mass and increase strength [59]. Furthermore, exercises, especially weight-bearing exercises, decrease pain scores, increase muscle strength, and might improve position sense [60]. All exercise programmes had a positive effect on pain. Walking and Nordic walking involves many large core and upper body muscles. Therefore, the impact of walking and NW on back and leg pain might have been stronger. There was also a tendency that hand pain was most improved by NW, which might be due to the required rhythmic hand opening and closing.

Nordic walking was only in some aspects superior to walking but improved postural stability, stride length, stride length variability, and percentage of double stance phase more than the other training programmes. These gait parameters seem to be important for a steady gait, and have major effects on mobility. Reduced stride length variability and a shorter double stance phase are associated with a lower risk of falling [39-41], while a reduction of stride length is associated with fear of falling [41]. Nordic walking was also most effective in improving walking speed on the motorized treadmill. Beauchet et al. [61] found a close relationship between slow walking speed and increased gait variability. Gait might be more unstable when subjects walk slower. Although we did not assess the most comfortable walking speed of the patients, the patients with lower gait variability felt more comfortable during walking compared to those with higher gait variability.

NW was most attractive for the patients, and all patients continued the training, which might be a prerequisite to maintain an active life style.

Supportive was that 70\% of the spouses took up NW and accompanied the patients after completion of the study. Since social aspects were very important for the PD patients, the participation of the spouses in NW might support further physical activity.

Physiotherapists should be encouraged to teach PD patients NW and to provide practise sessions with high intensity. Presumably the combination between motor learning, some flexibility exercises, and endurance training produces the best training effects. Three training lessons per week are necessary to learn the right technique and to improve cardiovascular fitness. A lower frequency of trainings sessions and lower intensity of the training in a previous study had been less effective. Exercise training should already be offered to patients in early stages of the disease to prevent a loss of muscle strength and a rapid decline of mobility. Nordic walking might also be suitable in advanced stages of $\mathrm{PD}$, since the support of the poles reduces the risk of falls. However, in advanced stages, fluctuations of motor symptoms and autonomic disturbances, such as exerciseinduced hypotension, have to be considered. In addition, at least some of the training sessions should be supervised, since patients do not notice their technical deficits.

The risk of injuries due to accidents during the training was low, but attention has to be drawn to a small risk of overuse injuries, especially of the shoulder, in NW. Therefore, an accompanying physiotherapy treatment is recommended, training should be supervised, and training frequency and intensity has to be gradually increased.

5.1. Limitations of the Study. We included patients in mildto-moderate stages of the disease and without a history of falls in the past. In another study (personal communication), we assessed the risk of falls in NW training in PD patients with frequent falls. Patients had been able to perform the training and did not sustain severe injuries. Patients participating in the current study did not suffer from severe concomitant diseases, which might have resulted in a positive selection of patients. Many patients of this age have significant concomitant diseases and might be less suitable for an aerobic exercise programme. Cognitive functions have not been formally assessed after completion of the training. Thus, the perception of the NW group, that they can better memorize and recall information, might be confounded by 
improved emotional well-being. Due to the lack of technical facilities, the exercise test did not include the measurement of $\mathrm{VO}_{2}$ consumption. Hence, we cannot comment on an improvement of fitness by the training.

\subsection{Probable Mechanisms Contributing to Beneficial Effects} of Exercise. Peripheral and central parameters might contribute to effects of exercise training. Better muscle coordination and recruitment, improvement of strength flexibility and increase of range of movements and balance reflect the peripheral mechanisms of adaptation to exercise. Cardiovascular effects and reduction of risk factors might contribute as well. In recent years, there is growing evidence from animal and human studies, that physical exercise enhances brain plasticity [62-65]. Physical activity modifies the release of dopamine and dopamine turnover and enhances the release of BDNF (brain-derived neurotrophic factor). These mechanisms might play an important role in central effects of physical activity $[66,67]$. Furthermore, BDNF improves neural plasticity and promotes axon outgrowth and development of synapses [67]. Thus, NW, when performed with higher intensity, might provoke a greater release of BDNF. Since walking with poles requires more coordination, interconnectedness might be promoted as well. Further studies are needed to approve these hypotheses.

In conclusion, the study has shown that all forms of exercises had some positive effects on symptoms and deficits caused by PD, but walking and Nordic walking, which involve aerobic endurance training, were superior to the flexibility and relaxation programme. Walking and Nordic walking reduced Parkinson-specific disability and pain, improved health-related quality of life, gait and led to a more active life style. However, PD patients needed more time to practise NW in order to obtain the necessary technical skills. Therefore, it might take longer for training effects to appear, since improvement of motor function is a prerequisite to participate in training sessions with higher intensity. Furthermore, patients showed adaptation to exercise. Participation in sports activities including aerobic training sessions has positive effects on daily activity, gait and PD-specific disability. Exercise therapy does not replace medication but is an important adjunct treatment. Prospective randomised long-term studies are needed to decide whether exercise therapy might also slow down the progression of Parkinson's disease.

\section{References}

[1] A. Schrag, Y. Ben-Shlomo, and N. P. Quinn, "Cross sectional prevalence survey of idiopathic Parkinson's disease and parkinsonism in London," British Medical Journal, vol. 321, no. 7252 , pp. 21-22, 2000.

[2] R. C. Chen, S. F. Chang, C. L. Su et al., "Prevalence, incidence, and mortality of PD: a door-to-door survey in Ilan County, Taiwan," Neurology, vol. 57, no. 9, pp. 1679-1686, 2001.

[3] T. H. Caradoc-Davies, M. Weatherall, G. S. Dixon, G. Caradoc-Davies, and P. Hantz, "Is the prevalence of Parkinson's disease in New Zealand really changing?" Acta Neurologica Scandinavica, vol. 86, no. 1, pp. 40-44, 1992.
[4] A. J. Hughes, S. E. Daniel, L. Kilford, and A. J. Lees, "Accuracy of clinical diagnosis of idiopathic Parkinson's disease: a clinico-pathological study of 100 cases," Journal of Neurology Neurosurgery and Psychiatry, vol. 55, no. 3, pp. 181-184, 1992.

[5] D. J. Gelb, E. Oliver, and S. Gilman, "Diagnostic criteria for Parkinson disease," Archives of Neurology, vol. 56, no. 1, pp. 33-39, 1999.

[6] M. B. Stern, "Parkinson's disease," in Parkinsonian Syndromes, M. B. Stern and W. C. Koller, Eds., Marcel Dekker, New York, NY, USA, 1993.

[7] H. L. Paulson and M. B. Stern, "Clinical manifestation of Parkinson's disease," in Movement Disorders Neurologic Principle and Practice, R. L. Ray and W. C. Koller, Eds., pp. 233-245, McGraw-Hill Medical, New York, NY, USA, 2004.

[8] R. Hassler, "Zur pathologie der paralysis agitans und des postenzephalitischen Parkinsonismus," Journal für Psychologie und Neurologie, vol. 48, pp. 387-476, 1938.

[9] O. Hornykiewicz, "Die topische Lokalisation und das Verhalten von Noradrenalin und Dopamin (3-Hydroxytyramin) in der substantia nigra des normalen und parkinsonkranken Menschen," Wiener Klinische Wochenschrift, vol. 75, pp. 309312, 1963.

[10] O. Hornykiewicz, "Dopamine (3-hydroxytyramine) and brain function," Pharmacological Reviews, vol. 18, no. 2, pp. 925964, 1966.

[11] A. Carlsson, M. Lindqvist, and T. Magnusson, "3,4dihydroxyphenylalanine and 5-hydroxytryptophan as reserpine antagonists," Nature, vol. 180, no. 4596, pp. 1200-1201, 1957.

[12] K. G. Lloyd, L. Davidson, and O. Hornykiewicz, "The neurochemistry of Parkinson's disease: effect of L Dopa therapy," Journal of Pharmacology and Experimental Therapeutics, vol. 195, no. 3, pp. 453-464, 1975.

[13] W. R. Gibb, “The neuropathology of Parkinson disorders," in Parkinson's Disease and Movement Disorders, J. Jankovic and E. Tolosa, Eds., pp. 205-233, Williams and Wilkins, Baltimore, Md, USA, 1993.

[14] W. C. Olanow, T. B. Freeman, and J. H. Kordower, "Transplantation and restorative therapies for Parkinson's disease," in Movement Disorders Neurologic Principles and Practice, R. L. Watts and W. C. Koller, Eds., McGraw-Hill Medical, New York, NY, USA, 2004.

[15] F. J. M. van Eijkeren, R. S. J. Reijmers, M. J. Kleinveld, A. Minten, J. P. ter Bruggen, and B. R. Bloem, "Nordic walking improves mobility in Parkinson's disease," Movement Disorders, vol. 23, no. 15, pp. 2239-2243, 2008.

[16] E. Fertl, A. Doppelbauer, and E. Auff, "Physical activity and sports in patients suffering from Parkinson's disease in comparison with healthy seniors," Journal of Neural Transmission, vol. 5, no. 2, pp. 157-161, 1993.

[17] M. Nallegowda, U. Singh, G. Handa et al., "Role of sensory input and muscle strength in maintenance of balance, gait, and posture in Parkinson's disease: a pilot study," American Journal of Physical Medicine and Rehabilitation, vol. 83, no. 12, pp. 898-908, 2004.

[18] L. M. Inkster, J. J. Eng, D. L. MacIntyre, and A. Jon Stoessl, "Leg muscle strength is reduced in Parkinson's disease and relates to the ability to rise from a chair," Movement Disorders, vol. 18, no. 2, pp. 157-162, 2003.

[19] V. A. Goodwin, S. H. Richards, R. S. Taylor, A. H. Taylor, and J. L. Campbell, "The effectiveness of exercise interventions for people with Parkinson's disease: a systematic review and metaanalysis," Movement Disorders, vol. 23, no. 5, pp. 631-640, 2008. 
[20] T. Ellis, C. J. de Goede, R. G. Feldmann, E. C. Wolters, G. Kwakkel, and R. C. Wagenaar, "Efficacy of a physical therapy programme in patients with Parkinson's disease: a randomized controlled trial," Archives of Physical Medicine and Rehabilitation, vol. 86, pp. 626-632, 2005.

[21] E. Brunelle and M. K. Miller, "The effects of walking poles on ground reaction forces," Research Quarterly for Exercise and Sport, vol. 3, pp. 30-31, 1998.

[22] N. K. Butts, K. M. Knox, and T. S. Foley, "Energy costs of walking on a dual-action treadmill in men and women," Medicine and Science in Sports and Exercise, vol. 27, no. 1, pp. 121-125, 1995.

[23] J. P. Porcari, T. L. Hendrickson, P. R. Walter, L. Terry, and G. Walsko, "The physiological responses to walking with and without power poles ${ }^{\mathrm{TM}}$ on treadmill exercise," Research Quarterly for Exercise and Sport, vol. 68, no. 2, pp. 161-166, 1997.

[24] H. Figard-Fabre, N. Fabre, A. Leonardi, and F. Schena, "Physiological and perceptual responses to Nordic walking in obese middle-aged women in comparison with the normal walk," European Journal of Applied Physiology, vol. 108, no. 6, pp. 1141-1151, 2010.

[25] M. M. Hoehn and M. D. Yahr, "Parkinsonism: onset, progression and mortality," Neurology, vol. 17, no. 5, pp. 427-442, 1967.

[26] R. J. Gibbons, G. J. Balady, J. T. Bricker et al., "ACC/AHA 2002 guideline update for exercise testing: summary article. A report of the American College of Cardiology/American Heart Association task force on practice guidelines (committee to update the 1997 exercise testing guidelines)," Circulation, vol. 106, no. 14, pp. 1883-1892, 2002.

[27] G. A. V. Borg, "Psychophysical bases of perceived exertion," Medicine and Science in Sports and Exercise, vol. 14, no. 5, pp. 377-381, 1982.

[28] S. Fahn and R. L. Elton, "members of UPDRS development committee," in Unified Parkinson's Disease Rating Scale, pp. 153-163, MacMillan Healthcare Information, Florham Park, NJ, USA, 1987.

[29] C. Jenkinson, R. Fitzpatrick, V. Peto, R. Greenhall, and N. Hyman, “The Parkinson's disease questionnaire (PDQ-39): development and validation of a Parkinson's disease summary index score," Age and Ageing, vol. 26, no. 5, pp. 353-357, 1997.

[30] A. S. Zigmond and R. P. Snaith, "The hospital anxiety and depression scale," Acta Psychiatrica Scandinavica, vol. 67, no. 6, pp. 361-370, 1983.

[31] M. F. Folstein, S. E. Folstein, and P. R. McHugh, “'Mini mental state. A practical method for grading the cognitive state of patients for the clinician," Journal of Psychiatric Research, vol. 12, no. 3, pp. 189-198, 1975.

[32] D. Mungas, "In-office mental status testing: a practical guide," Geriatrics, vol. 46, no. 7, pp. 54-66, 1991.

[33] W. W. Downie, P. A. Leatham, V. M. Rhind, V. Wright, J. A. Branco, and J. A. Anderson, "Studies with pain rating scales," Annals of the Rheumatic Diseases, vol. 37, no. 4, pp. 378-381, 1978.

[34] K. O. Berg, S. L. Wood-Dauphinee, J. I. Williams, and B. Maki, "Measuring balance in the elderly: validation of an instrument," Canadian Journal of Public Health, vol. 83, no. 2, pp. S7-S11, 1992.

[35] D. D. Webster, "Critical analysis of the disability in Parkinson's disease," Modern Treatment, vol. 5, no. 2, pp. 257-282, 1968.

[36] A. Gabell and U. S. L. Nayak, "The effect of age on variability in gait," Journals of Gerontology, vol. 39, no. 6, pp. 662-666, 1984.
[37] J. M. Hausdorff, Z. Ladin, and J. Y. Wei, "Footswitch system for measurement of the temporal parameters of gait," Journal of Biomechanics, vol. 28, no. 3, pp. 347-351, 1995.

[38] J. M. Hausdorff and F. Danion, "Stride variability: beyond length and frequency," Gait and Posture, vol. 20, no. 3, pp. 304$305,2004$.

[39] J. M. Hausdorff, M. E. Cudkowicz, R. Firtion, J. Y. Wei, and A. L. Goldberger, "Gait variability and basal ganglia disorders: stride-to-stride variations of gait cycle timing in Parkinson's disease and Huntington's disease," Movement Disorders, vol. 13, no. 3, pp. 428-437, 1998.

[40] J. M. Hausdorff, “Gait dynamics in Parkinson's disease: common and distinct behavior among stride length, gait variability, and fractal-like scaling," Chaos, vol. 19, no. 2, Article ID 026113, 14 pages, 2009.

[41] T. Nakamura, K. Meguro, and H. Sasaki, "Relationship between falls and stride length variability in senile dementia of the Alzheimer type," Gerontology, vol. 42, no. 2, pp. 108-113, 1996.

[42] B. E. Maki, "Gait changes in older adults: predictors of falls or indicators of fear?" Journal of the American Geriatrics Society, vol. 45, no. 3, pp. 313-320, 1997.

[43] A. Schrag, C. Sampaio, N. Counsell, and W. Poewe, "Minimal clinically important change on the Unified Parkinson's disease rating scale," Movement Disorders, vol. 21, no. 8, pp. 1200 1207, 2006.

[44] T. Schmitz-Hübsch, D. Pyfer, K. Kielwein, R. Fimmers, T. Klockgether, and U. Wüllner, "Qigong exercise for the symptoms of Parkinson's disease: a randomized, controlled pilot study," Movement Disorders, vol. 21, no. 4, pp. 543-548, 2006.

[45] M. Schenkman and R. B. Butler, "A model for multisystem evaluation treatment of individuals with Parkinson's disease," Physical Therapy, vol. 69, no. 11, pp. 932-943, 1989.

[46] M. Schenkman, M. Morey, and M. Kuchibhatla, "Spinal flexibility and balance control among community-dwelling adults with and without Parkinson's disease," Journals of Gerontology A, vol. 55, no. 8, pp. M441-M445, 2000.

[47] P. O. Mckeon, C. D. Ingersoll, D. C. Kerrigan, E. Saliba, B. C. Bennett, and J. Hertel, "Balance training improves function and postural control in those with chronic ankle instability," Medicine and Science in Sports and Exercise, vol. 40, no. 10, pp. 1810-1819, 2008.

[48] D. W. Bacharach, "Review of exercise physiology," in Clinical Exercise Physiology: Applications and Physiological Principles, L. LeMura and S. P. von Duvillard, Eds., Lippincott Williams \& Wilkins, Philadelphia, Pa, USA, 2003.

[49] I. Reuter, P. Leone, M. Schwed, and M. Oechsner, "Effect of Nordic walking in Parkinson's disease," Movement Disorders, vol. 21, article 567, 2006.

[50] S. H. J. Keus, B. R. Bloem, E. J. M. Hendriks, A. B. BrederoCohen, and M. Munneke, "Evidence-based analysis of physical therapy in Parkinson's disease with recommendations for practice and research," Movement Disorders, vol. 22, no. 4, pp. 451-460, 2007.

[51] S. Colcombe and A. F. Kramer, "Fitness effects on the cognitive function of older adults: a meta-analytic study," Psychological Science, vol. 14, no. 2, pp. 125-130, 2003.

[52] A. L. Behrman, J. H. Cauraugh, and K. E. Light, "Practice as an intervention to improve speeded motor performance and motor learning in Parkinson's disease," Journal of the Neurological Sciences, vol. 174, no. 2, pp. 127-136, 2000.

[53] C. G. Canning, L. Ada, and E. Woodhouse, "Multiple-task walking training in people with mild to moderate Parkinson's 
disease: a pilot study," Clinical Rehabilitation, vol. 22, no. 3, pp. 226-233, 2008.

[54] R. K. Stanley, E. J. Protas, and J. Jankovic, "Exercise performance in those having Parkinson's disease and healthy normals," Medicine and Science in Sports and Exercise, vol. 31, no. 6, pp. 761-766, 1999.

[55] M. E. Morris, R. Iansek, and B. Kirkwood, "A randomized controlled trial of movement strategies compared with exercise for people with Parkinson's disease," Movement Disorders, vol. 24, no. 1, pp. 64-71, 2009.

[56] M. E. Morris, C. L. Martin, and M. L. Schenkman, "Striding out with Parkinson disease: evidence-based physical therapy for gait disorders," Physical Therapy, vol. 90, no. 2, pp. 280 $288,2010$.

[57] V. Valderrabano, V. von Tscharner, B. M. Nigg et al., "Lower leg muscle atrophy in ankle osteoarthritis," Journal of Orthopaedic Research, vol. 24, no. 12, pp. 2159-2169, 2006.

[58] C. Slemenda, K. D. Brandt, D. K. Heilman et al., "Quadriceps weakness and osteoarthritis of the knee," Annals of Internal Medicine, vol. 127, no. 2, pp. 97-104, 1997.

[59] T. E. Jones, K. W. Stephenson, J. G. King, K. R. Knight, T. L. Marshall, and W. B. Scott, "Sarcopenia-mechanisms and treatments," Journal of Geriatric Physical Therapy, vol. 32, no. 2, pp. 39-45, 2009.

[60] M. H. Jan, C. H. Lin, Y. F. Lin, J. J. Lin, and D. H. Lin, "Effects of weight-bearing versus nonweight-bearing exercise on function, walking speed, and position sense in participants with knee osteoarthritis: a randomized controlled trial," Archives of Physical Medicine and Rehabilitation, vol. 90, no. 6, pp. 897-904, 2009.

[61] O. Beauchet, C. Annweiler, Y. Lecordroch et al., "Walking speed-related changes in stride time variability: effects of decreased speed," Journal of NeuroEngineering and Rehabilitation, vol. 6, no. 1, article 32, 2009.

[62] N. T. Lautenschlager, K. L. Cox, L. Flicker et al., "Effect of physical activity on cognitive function in older adults at risk for Alzheimer disease: a randomized trial," Journal of the American Medical Association, vol. 300, no. 9, pp. 1027-1037, 2008.

[63] W. Hollmann and H. K. Strüder, "Gehirn, Geist, Psyche und körperliche Aktivität," in Denken-Sprechen-Bewegen, J. R. Nitsch and H. Allmer, Eds., pp. 13-27, BPS, Köln, Germany, 2001.

[64] C. W. Cotman and N. C. Berchtold, "Exercise: a behavioral intervention to enhance brain health and plasticity," Trends in Neurosciences, vol. 25, no. 6, pp. 295-301, 2002.

[65] S. Vaynman, Z. Ying, and F. Gomez-Pinilla, "Hippocampal BDNF mediates the efficacy of exercise on synaptic plasticity and cognition," European Journal of Neuroscience, vol. 20, no. 10, pp. 2580-2590, 2004.

[66] K. Fabel and G. Kempermann, "Physical activity and the regulation of neurogenesis in the adult and aging brain," NeuroMolecular Medicine, vol. 10, no. 2, pp. 59-66, 2008.

[67] R. Meeusen, "Exercise and the brain: insight in new therapeutic modalities," Annals of Transplantation, vol. 10, no. 4, pp. 49-51, 2005. 


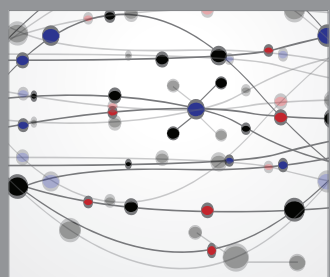

The Scientific World Journal
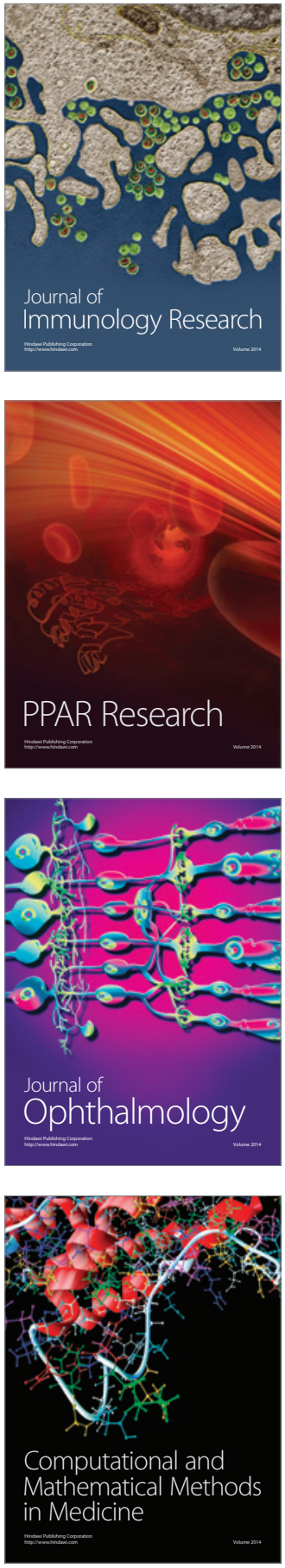

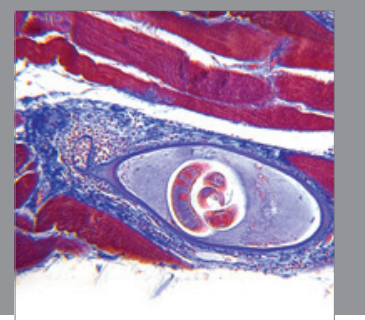

Gastroenterology

Research and Practice
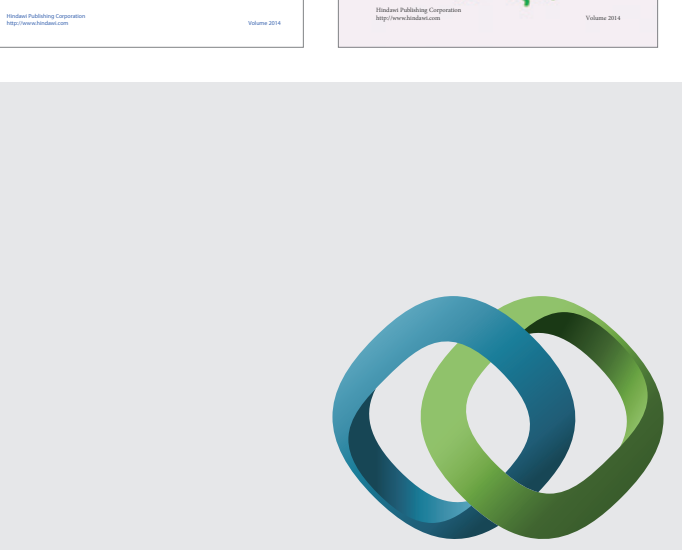

\section{Hindawi}

Submit your manuscripts at

http://www.hindawi.com
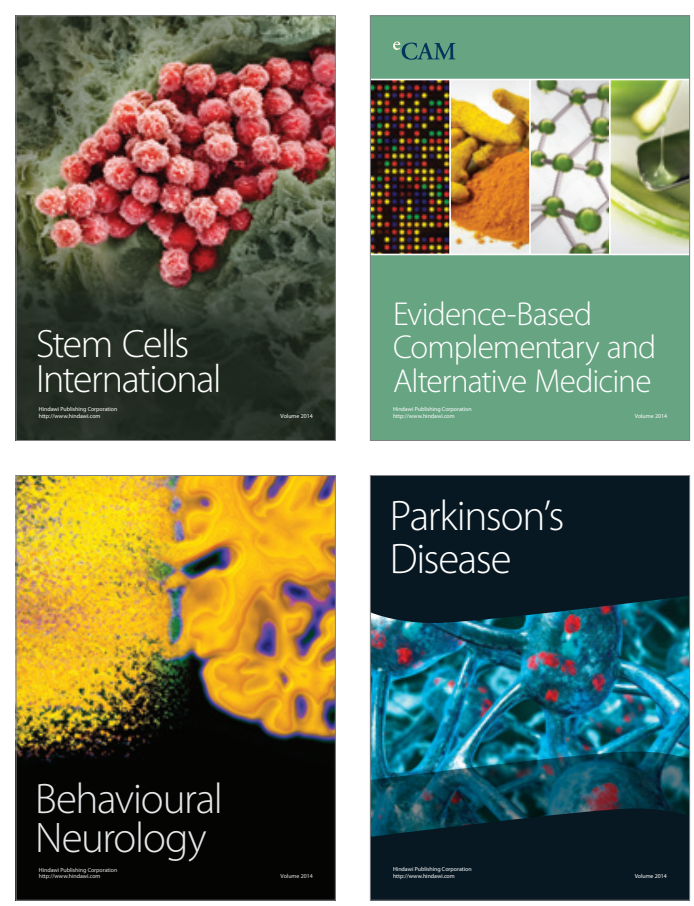

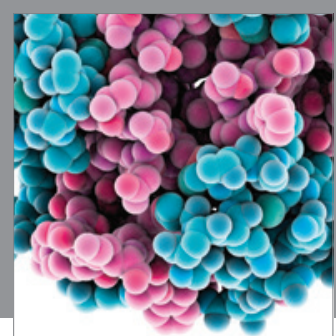

Journal of
Diabetes Research

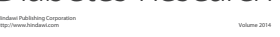

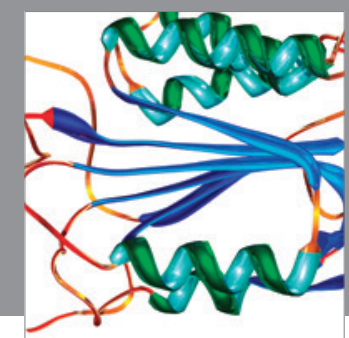

Disease Markers
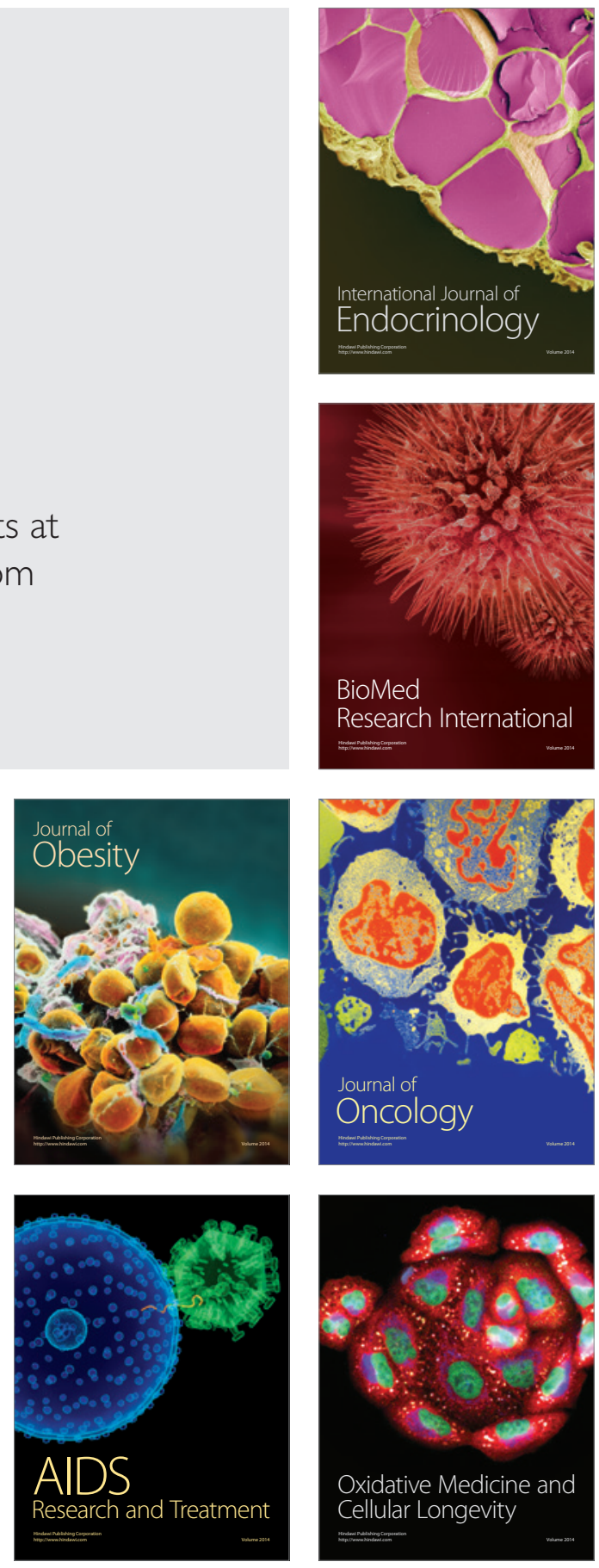